\title{
Mechanistic Studies into the Oxidative Addition of Co(I) Complexes: Combining Electroanalytical Techniques with Parameterization
}

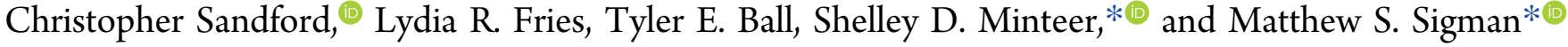

Department of Chemistry, University of Utah, 315 South 1400 East, Salt Lake City, Utah 84112, United States

Supporting Information

ABSTRACT: The oxidative addition of organic electrophiles into electrochemically generated $\mathrm{Co}(\mathrm{I})$ complexes has been widely utilized as a strategy to produce carbon-centered radicals when cobalt is ligated by a polydentate ligand. Changing to a bidentate ligand provides the opportunity to access discrete $\mathrm{Co}$ (III)-C bonded complexes for alternative reactivity, but knowledge of how ligand and/or substrate structures affect catalytic steps is pivotal to reaction design and catalyst optimization. In this vein, experimental studies that can determine the exact nature of elementary organometallic steps remain limited, especially for single-electron oxidative addition pathways. Herein, we utilize cyclic voltammetry combined with simulations to obtain kinetic and thermodynamic properties of the two-step, halogen-atom abstraction mechanism, validated by analyzing kinetic isotope and substituent effects. Complex Hammett relationships could be disentangled to allow understanding of individual effects on activation energy barriers and equilibrium constants, and DFT-derived parameters used to build predictive statistical models for rates of new ligand/substrate combinations.

\section{INTRODUCTION}

The oxidative addition of an electron-rich metal center into a carbon-heteroatom bond is a ubiquitous organometallic step involved in numerous key synthetic transformations. ${ }^{1}$ The mechanism of oxidative addition is highly dependent on both the metal complex and the substrate involved and can proceed through a variety of polar and/or radical intermediates. Thereby, knowledge of the mechanism enables the prediction of reactivity.

For example, the application of modern one-electron processes in nickel catalysis, including photoredox catalysis and electrocatalysis, has facilitated the development of a range of nickel-catalyzed synthetic transformations, which proceed through radical intermediates. ${ }^{2}$ Two-electron processes have also been widely implicated for the oxidative addition of nickel into alkyl-heteroatom bonds, and the dichotomy of these pathways has been extensively studied by DFT. ${ }^{3-5}$ However, identifying experimental techniques to probe these distinctions remains a challenge, due to the multiple reaction steps involved. In this context, Diao and co-workers recently provided the first experimental evidence that Xantphos-ligated $\mathrm{Ni}(\mathrm{I})$ complexes react with unactivated alkyl bromides by halogen-atom abstraction, interrogated using a range of kinetic studies, and supplemented by DFT computations.

As part of our emerging program to investigate the subtle effects of molecular structure on fundamental organometallic reactivity, we herein leverage electroanalytical techniques to study how the reactivity of $\mathrm{Co}(\mathrm{I})$ complexes compares mechanistically to nickel systems. While Co(I) complexes ligated by polydentate ligands have been broadly used as a source of carbon-centered radicals in solution, ${ }^{7,8}$ comparatively little is understood about the modes of activation of cobalt complexes with bidentate ligands. ${ }^{9}$ In analogy to similar reactivities of $\mathrm{Ni} / \mathrm{Pd} / \mathrm{Cu}$ species, it is feasible that several different mechanisms could be in operation: concerted polar oxidative addition, $\mathrm{S}_{\mathrm{N}} 2$-type oxidative addition, outer-sphere electron transfer, or halogen-atom abstraction (Scheme 1). ${ }^{6,10,11}$

Having previously studied how electronic manipulations of the $N, N$-bidentate ligand structure reduce deleterious disproportionation reactions of $\mathrm{Co}(\mathrm{I})$ complexes, ${ }^{12}$ we identified that pyridine-oxazoline (pyrox) ligands are promising candidates for designing electrocatalytic systems. Nevertheless, without knowledge of the mechanism of the fundamental organometallic steps that occur in a catalytic cycle, it is difficult to predict combinations of substrate and catalyst that are kinetically and thermodynamically facile for applications in catalysis. Indeed, to gain a complete picture of the complex oxidative addition mechanism unveiled herein, it was necessary to employ a combination of electroanalytical measurements and simulations, ${ }^{13}$ along with modern physical organic tools, ${ }^{14}$ to disentangle multiple reaction steps. With the ultimate goal of designing new catalytic transformations in mind, the

Received: October 7, 2019

Published: November 8, 2019 
Scheme 1. (a) Study into the Mechanism of Oxidative Addition of Co(I) Complexes; and (b) Possible Transition States/Intermediates for Oxidative Addition Processes

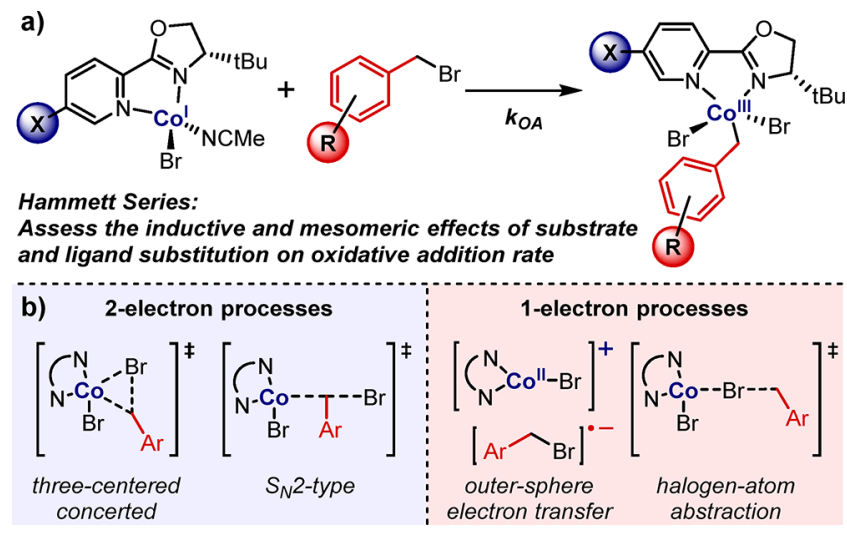

techniques developed throughout this study are widely applicable to investigating the intricate factors, which lead to catalytic activity across a number of organometallic systems.

\section{RESULTS AND DISCUSSION}

2.1. Determination of Oxidative Addition Rate Constants. To determine the rate constant for oxidative addition, we conducted cyclic voltammetric $(\mathrm{CV})$ studies with a solution containing 1 equiv of $\mathrm{CoBr}_{2}, 1$ equiv of pyrox ligand, and 1 equiv of benzyl bromide substrate, using a boron-doped diamond working electrode. Boron-doped diamond was used due to the high overpotential for the hydrogen evolution reaction at the electrode surface. ${ }^{15}$ According to our previous study, ${ }^{12}$ we first used square wave voltammetry to ascertain the concentration of monoligated complex in solution. Next, we conducted a series of $\mathrm{CVs}$ performed at various scan rates across an electrochemical window limited to the $\mathrm{Co}(\mathrm{II}) / \mathrm{Co}(\mathrm{I})$ redox couple of the monoligated complex. Comparing the ratio of peak currents in the forward $\left(i_{\mathrm{pc}}\right)$ and reverse $\left(i_{\mathrm{pa}}\right)$ scans enables calculation of the quantity of $\mathrm{Co}(\mathrm{I})$ complex consumed by oxidative addition during the $\mathrm{CV}$ scan. ${ }^{8 \mathrm{~b}}$ Altering the scan rate of the $\mathrm{CV}$ changes the time allowed for the oxidative addition between the two peak-current measurements, thus changing the ratio of peak currents (Figure 1). Plotting multiple peak-current ratios versus time according to standard second-order kinetics thereby facilitates measurement of the oxidative addition rate constant. For a more detailed explanation of this technique, we direct the reader to previous studies. $^{8 \mathrm{~b}, 12,16}$

Measurements of oxidative addition in this manner can be rapidly ascertained (average time for collection of one rate constant of 15-30 $\mathrm{min}$ ), and we collected repeat measurements for each substrate/ligand complex studied. We note that the measurement of the rate constant in this manner can only be made in scenarios where the oxidative addition is significantly faster (ideally at least 1 order of magnitude) than disproportionation of the reactive $\mathrm{Co}(\mathrm{I})$ complex. Additionally, when the oxidative addition is too fast such that the reverse peak cannot be observed even at very fast scan rates, this technique is no longer applicable. This can also occur when the oxidative addition is catalytic, reforming a $\mathrm{Co}$ (II) species following reaction with the substrate such that a catalytic current is observed (an EC' mechanism was observed with $2,2^{\prime}$-bipyridyl ligated $\mathrm{Co}(\mathrm{I})$ complexes $\left.^{12}\right)$. Under these

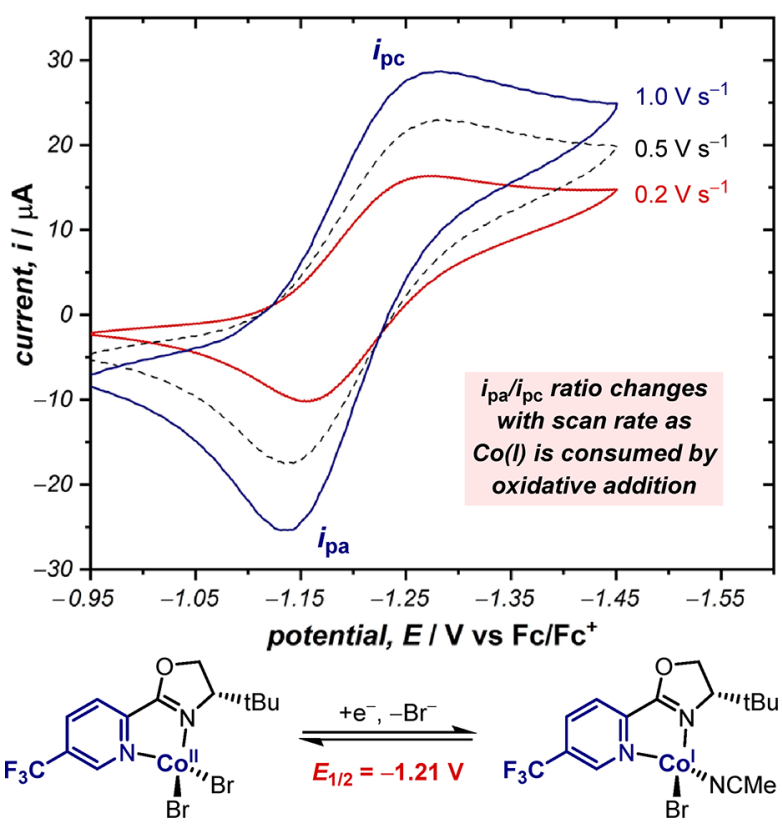

Figure 1. Variation in peak-current ratio $\left(i_{\mathrm{pa}} / i_{\mathrm{pc}}\right)$ as a function of scan rate enables measurement of the rate constant of oxidative addition occurring during the $\mathrm{CV}$ scan. CVs of $1.0 \mathrm{mM} \mathrm{Co}(\mathrm{I})$ complex in the presence of $1.0 \mathrm{mM}$ benzyl bromide at varying scan rates in a $100 \mathrm{mM}$ solution of $\mathrm{Bu}_{4} \mathrm{NPF}_{6}$ in acetonitrile, using a $0.071 \mathrm{~cm}^{2}$ boron-doped diamond working electrode. CVs are plotted in polarographic notation with positive currents corresponding to reduction.

conditions, one can use the shift in peak potential to measure reaction rates (see section 2.3 ). ${ }^{8 \mathrm{~d}, 13 \mathrm{a}}$

2.2. Hammett Studies. Having determined the relative rate constants for a variety of para- and meta-substituted benzyl bromides, we performed a Hammett-type analysis by comparing correlations with various tabulated Hammett $\sigma$ values. ${ }^{17}$ With cyano-substituted pyrox ligand $\mathbf{1}$, we observed the best fit for separately correlating electron-rich substrates with $\sigma^{+}$, and electron-deficient substrates with $\sigma^{-}$(Figure 2a). A similar pair of correlations was observed with trifluoromethyl-substituted pyrox ligand 2 (Figure $2 \mathrm{~b}$ ), except that the rate constants for oxidative addition were determined to be a factor of 4 greater on average, which is in agreement with a more electron-rich ligand increasing the rate for oxidation of nucleophilic $\mathrm{Co}$ (I) to $\mathrm{Co}(\mathrm{III})$.

The contrasting behaviors with electron-rich and electrondeficient substrates suggest a change in mechanism between stabilization of a positive and negative charge in the transition state, respectively. Previously, curved and broken Hammett relationships have been observed for $S_{\mathrm{N}} 2$ reactions at benzylic sites as a result of structural variations in the transition state, ${ }^{19}$ and also for organometallic reactions involving a change in rate-determining step between oxidative addition and reductive elimination. ${ }^{20}$ While a break in a Hammett relationship between separate correlations using $\sigma$ and $\sigma^{+}$parameters or para- and meta-substituents is not uncommon, ${ }^{21}$ a break between $\sigma^{+}$and $\sigma^{-}$is very unusual.

Alternatively, the deviation in the Hammett relationship may be a consequence of the stabilization of a radical intermediate, which would yield increased rate constants with either mesomerically donating or withdrawing groups. However, generally poor correlations were observed when using a variety of radical-based substituent parameters $\left(R^{2}<0.75\right.$ in all cases, 

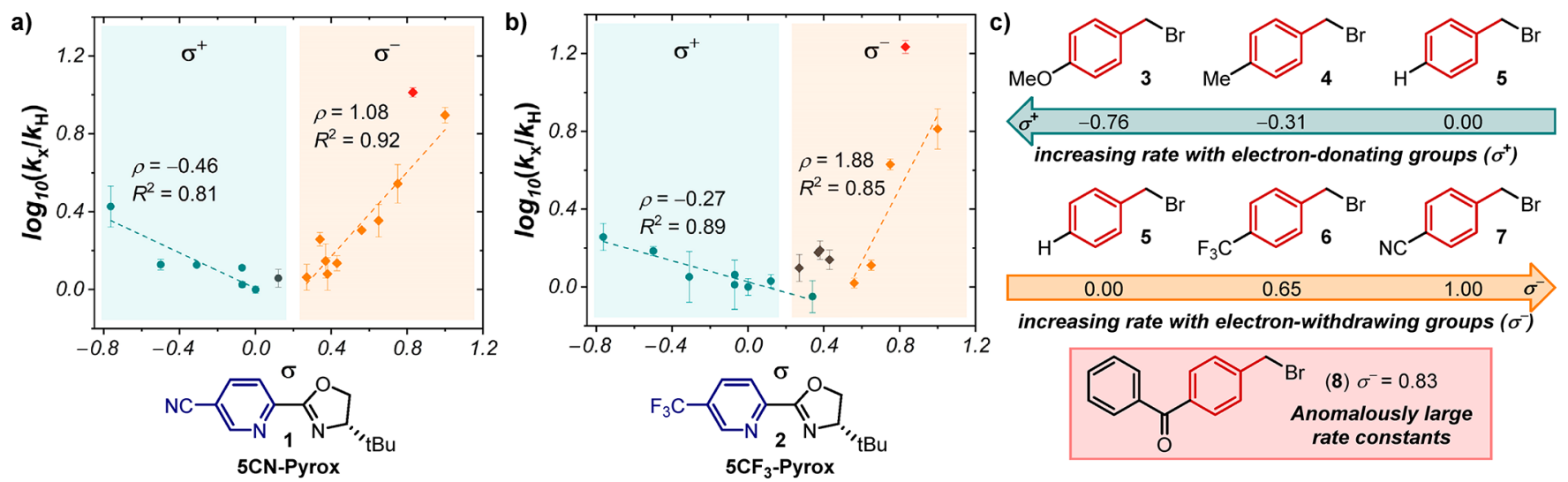

Figure 2. Hammett plots for oxidative addition into benzyl bromides by $\mathrm{LCo}(\mathrm{I}) \mathrm{Br}$ ligated by (a) $5 \mathrm{CN}$-substituted pyrox 1 and (b) $5 \mathrm{CF}_{3}$ substituted pyrox 2 . The lines with negative correlations use $\sigma^{+}$values, while the lines with positive correlations use $\sigma^{-}$values (taken from the pKa of the corresponding aniline or phenol). ${ }^{17 a, 18}$ Error bars depict the standard error of the mean for between 2 and 5 measurements. (c) Trends and anomaly in oxidative addition rate constants observed from the Hammett plots, with selected example substrates depicted.

as an average for the two ligands; see the Supporting Information), ${ }^{22}$ suggesting against singular stabilization of a radical intermediate (see section 2.7 for further information).

Additionally, in both Hammett studies, we observed the same outlier, para-COPh benzyl bromide (8, depicted in red). The presence of this outlier suggests an additional mechanism may be in operation. Benzophenone is a known reductive mediator, ${ }^{23}$ and we determined the half-peak potential $\left(E_{\mathrm{p} / 2}\right)^{13 \mathrm{a}, 24}$ for this bromide substrate to be $570 \mathrm{mV}$ more negative than the $\mathrm{Co}(\mathrm{II}) / \mathrm{Co}(\mathrm{I})$ redox couple with ligand 2, which by itself appears to contradict an electron-transfer mechanism. However, it is important to consider that this heterogeneous electron transfer at the boron-doped diamond working electrode may be kinetically slow, leading to a large overpotential for substrate reduction. It is therefore feasible that the thermodynamic reduction potential lies close to or less negative than the $\mathrm{Co}(\mathrm{II}) / \mathrm{Co}(\mathrm{I})$ couple, and a single electrontransfer mechanism should not be discounted at this stage. Furthermore, it is possible that this electron transfer is induced photochemically by the formation of a charge-transfer complex $^{25}$ or reduction of a photoexcited state; ${ }^{26}$ however, this scenario was discounted by measuring the same rate constant with and without visible light.

2.3. Dependence of Peak Current and Potential on Substrate Concentration. To provide further insight into the different oxidative addition mechanisms, we next conducted $\mathrm{CV}$ experiments with varying concentrations of substrate. In this experiment, if $\mathrm{Co}$ (II) is returned in the reaction, one would expect to observe a sequential increase in current as more benzyl bromide is added, indicative of an EC' (catalytic) mechanism, which we had previously observed with $2,2^{\prime}$-bipyridyl (bpy) as the ligand for cobalt. ${ }^{12}$ This behavior was not observed for any substrate with either pyrox ligand, and the peak current was found to be minimally dependent on substrate concentration.

In contrast to electrochemical catalysis, the peak potential for an EC mechanism (electrochemical reduction, "E", followed by a chemical step directly forming $\mathrm{Co}$ (III), "C") should display an anodic shift (to less negative potentials) with increasing substrate concentration. This is indicative of depleting the solution near the electrode of $\mathrm{Co}(\mathrm{I})$ and shifting the Nernstian equilibrium accordingly. ${ }^{8 \mathrm{~d}}$ However, we observed the opposite; a cathodic shift with increasing substrate concentration is displayed by all of the substratecatalyst combinations tested (Figure 3 ). These data point to an

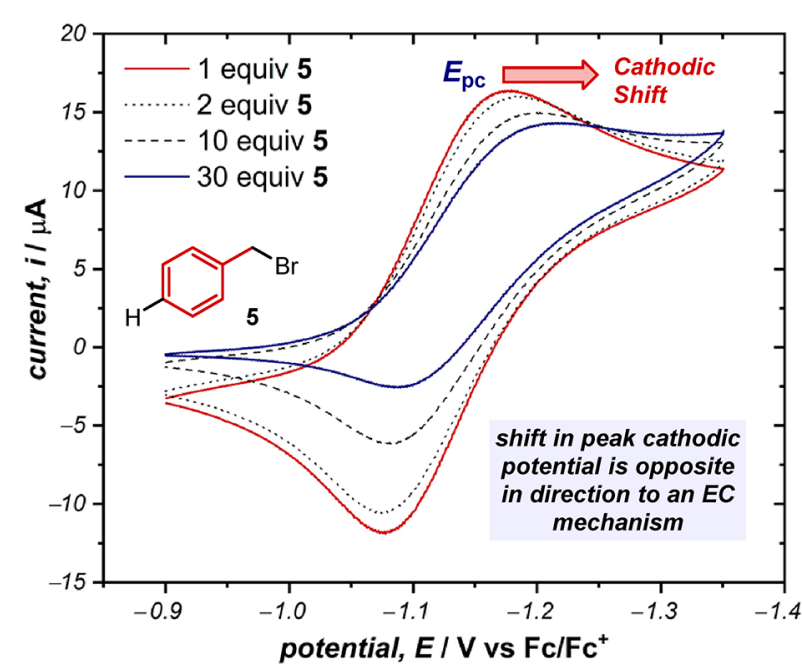

Figure 3. Cathodic shift of peak cathodic potential for the Co(II)/ $\mathrm{Co}(\mathrm{I})$ couple ligated by $5 \mathrm{CN}$-pyrox 1 with successive increases in benzyl bromide (5) concentration is not consistent with an EC mechanism. CVs run with $1.0 \mathrm{mM} \mathrm{CoBr} 2$ with $1.0 \mathrm{mM} 1$ at varying equivalents of 5 in a $100 \mathrm{mM}$ solution of $\mathrm{Bu}_{4} \mathrm{NPF}_{6}$ in acetonitrile, using a $0.071 \mathrm{~cm}^{2}$ boron-doped diamond working electrode at a scan rate of $100 \mathrm{mV} \mathrm{s}^{-1}$. CVs are plotted in polarographic notation with positive currents corresponding to reduction.

alternative mechanism entirely to the postulated EC process, and suggest a second electrochemical or chemical step is involved in the oxidative addition mechanism. Because the rate constants $\left(k_{\text {obs }}\right)$ correlated above are then compounded rate constants of multiple reaction steps, this is in agreement with the unusual broken Hammett relationships observed.

To identify the nature of the multiple-step reaction, voltammetric simulations using DigiSim 3.03 b software were performed to determine the magnitude of the cathodic shift, in combination with the simulated overall rate constant, $k_{\mathrm{obs}}$. Electrochemical finite element and finite difference simulations are used to formulate a theoretical current response as a function of experimental conditions and physical knowns and unknowns. ${ }^{13 a, 27}$ Although multiple assertions are required to 
estimate some values that are inputs in the simulation (see the Supporting Information for details), comparing trends in the theoretical response against experiment (e.g., the magnitude of the cathodic shift vs equivalents of substrate) facilitates approximation of the physical unknowns, in this case, the kinetics and thermodynamics of various reaction steps, which can be validated by simulated cyclic voltammograms under different conditions (concentrations, scan rate, etc.).

Using this method, possible scenarios involving the presence of comproportionation steps ${ }^{2 c, 28}$ and/or a second electrochemical step could be discounted. A good match with the experimental data was observed for an initial formation of $\mathrm{CoBr}_{2}$ and a carbon-centered benzylic radical, followed by an equilibrium for $\mathrm{Co}(\mathrm{III})-\mathrm{C}$ bond formation (Figure 4). The

a)

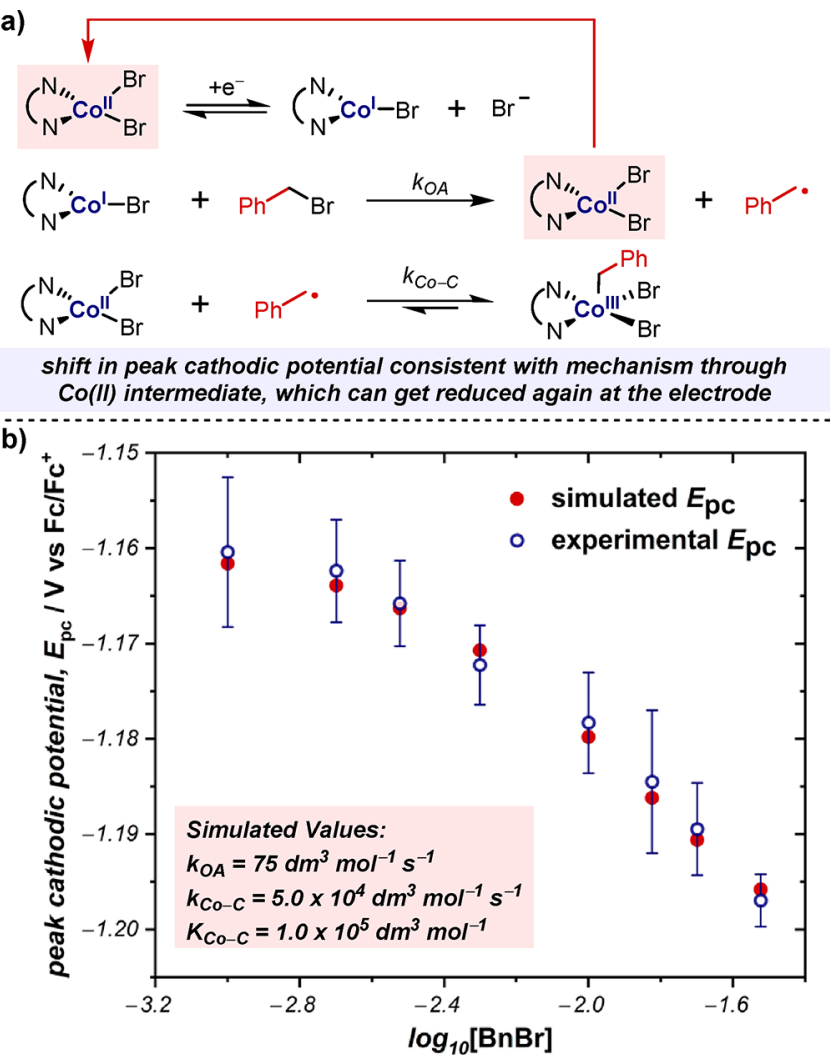

Figure 4. (a) Proposed oxidative addition mechanism, with (b) experimental results in agreement with simulation (error bars represent one standard deviation from 3-6 repeat experiments, $\mathrm{Co}(\mathrm{I})$ ligated by $5 \mathrm{CN}$-pyrox 1 in the presence of 5 ).

equilibrium formation of $\mathrm{Co}$ (III) $-\mathrm{C}$ explains differences in $\mathrm{CV}$ responses with bpy and pyrox: for pyrox ligands, the equilibrium lies toward the formation of $\mathrm{Co}$ (III) leading to EC-type CV responses, while with bpy the equilibrium shifts to favor $\mathrm{Co}(\mathrm{II})$. Because the $\mathrm{Co}(\mathrm{II})$ at the electrode becomes rapidly reduced back to $\mathrm{Co}(\mathrm{I})$, this results in catalysis $\left(\mathrm{EC}^{\prime} \mathrm{CV}\right.$ response) with increasing currents as the substrate concentration increases. $^{12}$

Additionally, these simulations provide plausible changes in Gibbs free energies for the various steps (oxidative addition of benzyl bromide 5 with $\mathrm{Co}(\mathrm{I})$ ligated by $5 \mathrm{CN}$-pyrox 1): an activation energy barrier of $14.9 \mathrm{kcal} \mathrm{mol}^{-1}$ for the initial oxidative addition step, and a subsequent barrier of $11.0 \mathrm{kcal}$ $\mathrm{mol}^{-1}$ for addition of the benzylic radical to $\mathrm{Co}$ (II), with a $-6.8 \mathrm{kcal} \mathrm{mol}^{-1}$ exergonic reaction to form $\mathrm{Co}(\mathrm{III}){ }^{29}$ Deriving thermochemical data directly from simulating experimental outputs in this manner provides direct access to information on the intricate factors that affect multiple sequential reactions, while changing the $\mathrm{CV}$ scan rate alone only identifies the net kinetic result.

These results can be compared to DFT computations derived for similar oxidative additions of nickel and subsequent reversible $\mathrm{Ni}(\mathrm{III})-\mathrm{C}$ bond formation/cleavage. ${ }^{4 \mathrm{~b}, 6,30}$ Indeed, the low $\left(4 \mathrm{kcal} \mathrm{mol}^{-1}\right)$ barrier for addition of benzylic radicals to a $\mathrm{Ni}($ bpy $) \mathrm{PhBr}$ complex determined by the groups of Kozlowski and Molander enables a dynamic kinetic resolution (DKR) to induce the formation of enantioenriched products from racemic starting materials in the presence of a chiral bioxazoline ligand. ${ }^{30 a}$ Because our simulated barrier is greater than this, DKR is possible but less kinetically facile with this cobalt catalyst system than with chiral derivatives of $\mathrm{Ni}(\mathrm{bpy})$ $\mathrm{PhBr}$.

Overall, at this stage, concerted polar or $\mathrm{S}_{\mathrm{N}} 2$ reaction mechanisms can be ruled out as the intermediacy of a discrete carbon-centered radical is consistent with the data. This provides indirect evidence that either a halogen-atom abstraction (inner-sphere) mechanism or an outer-sphere electron transfer is operational.

2.4. Analyzing the Impact of Electronics on the Individual Mechanistic Steps. As a consequence of the thermochemical data, which are available through simulation of experimental voltammetric results, we next conducted a series of experiments to ascertain the impact of changing the substrate and/or ligand on the two steps in the overall reaction: (a) formation of the benzylic radical, and (b) the reversible combination of the benzylic radical with $\mathrm{Co}$ (II) to afford a $\mathrm{Co}$ (III) $-\mathrm{C}$ bond. A subset of the substrate Hammett series was selected, selecting electron-rich, -neutral, and -deficient substrates (Figure 5).

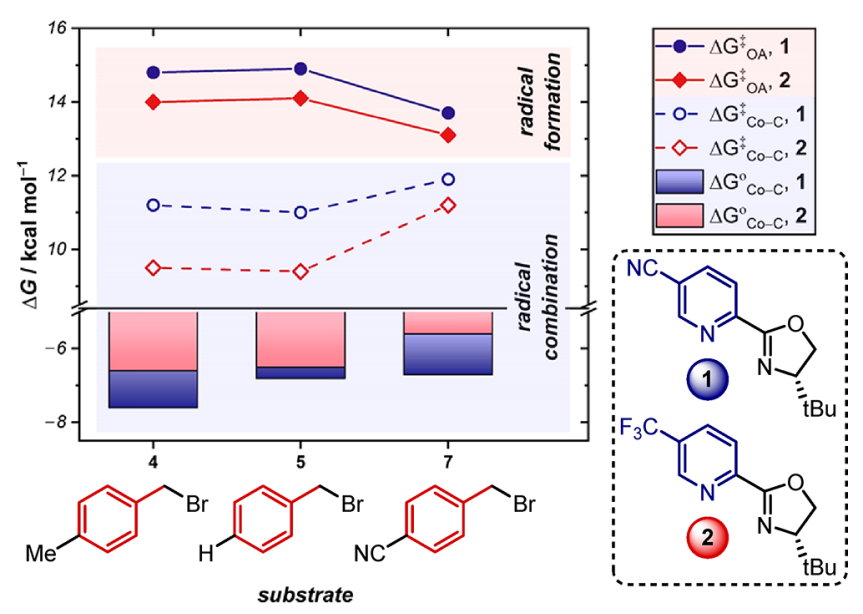

Figure 5. Graphical depiction of free-energy data for the two steps of the oxidative addition process derived from $\mathrm{CV}$ simulations. $\mathrm{OA}$ is the formation of benzylic radicals, and $\mathrm{Co}-\mathrm{C}$ the subsequent formation of the $\mathrm{Co}(\mathrm{III})$ complex.

Comparing the substrate effects on the formation of the benzylic radical, the activation barrier is lowered by adding either an electron-donating methyl or an electron-withdrawing cyano-group on the aromatic, consistent with stabilization of the resulting radical (Scheme $2 \mathrm{a}$ ). This suggests that the rate is not determined by an initial outer-sphere electron transfer, where one would expect the methyl group to raise the LUMO 
Scheme 2. Ligand and Substrate Effects on (a) the Formation of the Benzylic Radical, and (b) the Equilibrium Formation of $\mathrm{Co}(\mathrm{III})-\mathrm{C}$

a) Radical formation:

$$
\text { Increased rate constant with (i) Electron-rich ligand, and (ii) Substrate which }
$$
can stabilize a radical more effectively (not an electron transfer)

b) Radical combination

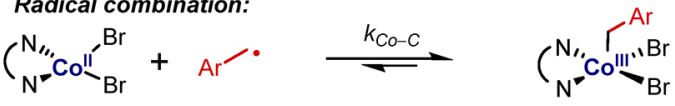

Increased rate constant with (i) Electron-rich ligand, and (ii) Substrate which can stabilize a radical less effectively

ncreased equilibrium constant with (i) Electron-deficient ligand, and (ii) Electron-rich (more nucleophilic) substrate

of the aromatic ring and slow the electron transfer. Similarly, the rate of the addition of the benzylic radical is also determined by radical stability; the least stabilized radical derived from substrate $\mathbf{5}$ has the lowest barrier to addition to cobalt (Scheme 2b).

In contrast to the activation energy barriers, the exergonicity of the formation of the terminal $\mathrm{Co}$ (III) $-\mathrm{C}$ complex appears to be controlled more by electron density on the benzylic carbon rather than radical stability; removing electron density by replacing an electron-donating substituent with an electronwithdrawing substituent shifts the equilibrium toward the initial benzylic radical. This suggests that the thermodynamics of this step are controlled by aspects of nucleophilicity; the electron-withdrawing cyano-substituent of substrate 7 reduces the stabilization afforded by binding to the cobalt center, because the partial negative charge is in conjugation with the electron-withdrawing group.

Comparing the effect of the two ligands, the more electronwithdrawing ligand (1) increases both activation barriers as well as increasing the exergonicity of the equilibrium. As discussed above (section 2.2), the reduced rate with ligand $5 \mathrm{CN}$-pyrox 1 is indicative of a less nucleophilic $\mathrm{Co}(\mathrm{I})$ complex that slows oxidative addition. The shift in the equilibrium position is in agreement with greater stabilization of the more electrophilic $\mathrm{Co}$ (III) center by an additional X-type benzyl ligand.

2.5. Secondary Substrates. To understand the precise nature of the first step in the oxidative addition, the formation of a benzylic radical, we next chose to study the effect of changing from a primary to a secondary and tertiary benzylic substrate (Table 1). It was found that secondary bromide substrates consistently react with a greater rate constant than their primary counterparts. This is not consistent with either an $\mathrm{S}_{\mathrm{N}} 2$ or a concerted polar-type oxidative addition, which would both proceed through more sterically hindered transition states than for primary substrates, in agreement with the one-electron mechanism determined by simulating the CVs above. An outer-sphere electron transfer is also not supported by this mechanism, because electron donation from the methyl group makes the aromatic ring more electron-rich, thereby raising the LUMO.

To interrogate these results further, we turned our attention to the chloride series, given that the tertiary bromide is highly unstable to E1 elimination. The parent primary benzyl chloride (9) reacts with the $\mathrm{Co}(\mathrm{I})$ complex ligated by 2 with a substantially reduced rate as compared to benzyl bromides as a consequence of the greater $\mathrm{C}-\mathrm{Cl}$ bond strength. Upon

\begin{tabular}{|c|c|c|c|}
\hline Ligand & Substrate & $k_{2^{\circ}} / k_{1^{\circ}}$ & $k_{3^{\circ}} / k_{1^{\circ}}$ \\
\hline $\begin{array}{c}\text { 5CN-Pyrox } \\
\text { (1) }\end{array}$ & 5 & $2.24 \pm 0.44$ & n.d. \\
\hline $\begin{array}{c}\text { 5CN-Pyrox } \\
\text { (1) }\end{array}$ & 7 & $1.51 \pm 0.03$ & n.d. \\
\hline $\begin{array}{c}\text { 5CN-Pyrox } \\
\text { (1) }\end{array}$ & 8 & $3.21 \pm 0.10$ & n.d. \\
\hline $\begin{array}{c}5 \mathrm{CF}_{3}-\text { Pyrox } \\
\text { (2) }\end{array}$ & 5 & $2.36 \pm 0.37$ & n.d. \\
\hline $\begin{array}{c}5 \mathrm{CF}_{3}-\text { Pyrox } \\
\text { (2) }\end{array}$ & 7 & $1.14 \pm 0.32$ & n.d. \\
\hline $\begin{array}{c}5 \mathrm{CF}_{3}-\text { Pyrox } \\
\text { (2) }\end{array}$ & $\mathrm{BnCl}(\mathbf{9})$ & $1.30 \pm 0.35$ & $1.65 \pm 0.35$ \\
\hline
\end{tabular}

Table 1. Relative Rate Constants for Primary, Secondary, and Tertiary Substrates ${ }^{a}$

${ }^{a}$ Error bars are one standard deviation based on the variance of the secondary/tertiary substrate rate constant (for 3-5 repeat experiments). n.d. = not determined.

changing to a secondary and tertiary substrate, respectively, the rate increases consecutively. The smaller effect of the secondary substrate in rate enhancement observed with benzyl chloride in comparison with the bromide analogue suggests that the transition state is earlier in the case of chloride due to the greater $\mathrm{C}-\mathrm{Cl}$ bond strength. In this scenario, the reaction coordinate from starting material to an early transition state is accompanied by a reduced change in hybridization from $\mathrm{sp}^{3}$ to $\mathrm{sp}^{2}$, thereby diminishing the stabilization afforded by hyperconjugation from the methyl substituents. ${ }^{2 a}$

Finally, we also investigated the effect of changing benzophenone substrate $\mathbf{8}$ to the corresponding secondary analogue. Given that we earlier proposed that an outer-sphere electron transfer is in operation for this anomalous substrate, our hypothesis was that the secondary substrate would react with a reduced rate, consistent with the higher LUMO. Upon testing this, we determined that, with $5 \mathrm{CN}$-pyrox $1, k_{2^{\circ}} / k_{1^{\circ}}=$ $3.21 \pm 0.10$, in direct contradiction with our expectation for an outer-sphere electron transfer. Indeed, this evidence points toward a halogen-atom transfer mechanism, even though this substrate was found to be anomalous in the Hammett plots. The reasoning behind this discrepancy was discovered through our multivariable linear-regression studies; see section 2.9.

2.6. Kinetic Isotope Effect Study. Further validation of the halogen-atom abstraction mechanism was provided by studying the secondary kinetic isotope effect (KIE) ${ }^{31}$ of replacing protons with deuterium nuclei bonded to the benzylic carbon, which provides information on changes in hybridization in the transition state. Studies of various oxidative addition $^{32}$ and organohalide reduction ${ }^{33}$ mechanisms by this technique have previously been used to differentiate between mechanisms based upon the magnitude of the KIE.

Investigating the combination of substrate 7 and its deuterated analogues $7-\boldsymbol{d}_{1}$ and $7-\boldsymbol{d}_{2}$ in the presence of $\mathrm{CoBr}_{2}$ ligated by $5 \mathrm{CF}_{3}$-pyrox 2 , a normal $(>1.0)$ secondary $\mathrm{KIE}$ was observed (Figure 6a), indicative of a change from $\mathrm{sp}^{3}$ to $\mathrm{sp}^{2}$ hybridization. The average KIE of $1.52 \pm 0.28$ is larger than a 
a)
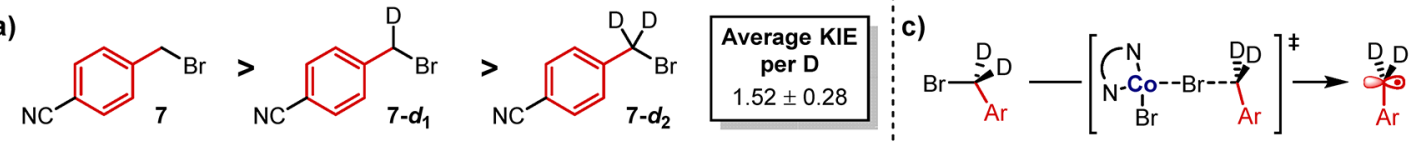

$s p^{3}$ to $s p^{2}$ hybridization

change leads to normal secondary KIE

\begin{tabular}{|c|c|c|c|}
\hline Substrate & 7 & $7-d_{2}$ & $\begin{array}{c}\text { Result of } \\
\text { Simulations }\end{array}$ \\
\hline$\Delta \mathrm{G}^{+} \mathrm{OA} / \mathrm{kcal} \mathrm{mol}^{-1}$ & 13.1 & 13.6 & Normal KIE \\
\hline$\Delta \mathrm{G}^{*} \mathrm{Co-C} / \mathrm{kcal} \mathrm{mol}^{-1}$ & 11.2 & 9.9 & Inverse KIE \\
\hline$\Delta \mathrm{G}^{\circ} \mathrm{Co- \textrm {C }} / \mathrm{kcal} \mathrm{mol}^{-1}$ & -5.6 & -5.5 & EIE \\
\hline
\end{tabular}

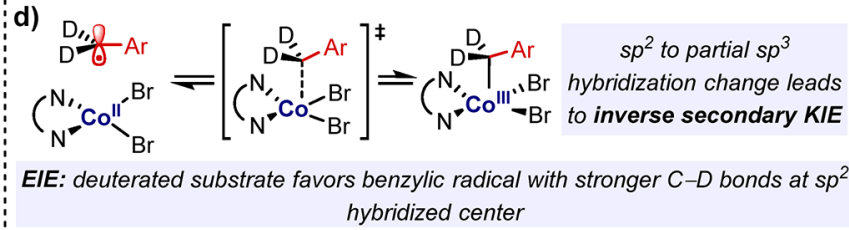

Figure 6. (a) Trend in rate constants for protonated and deuterated analogues of substrate 7 , with $5 \mathrm{CF}_{3}$-pyrox 2 . For raw data and comparisons with other deuterated substrate/ligand combinations, see the Supporting Information. (b) Result of simulations comparing substrate 7 and $7-\boldsymbol{d}_{2}$. (c) Change in hybridization leading to a normal KIE in the formation of the benzylic radical. (d) KIE and EIE effects in radical combination with $\mathrm{Co}$ (II) to form a $\mathrm{Co}(\mathrm{III})-\mathrm{C}$ complex. OA is the formation of benzylic radicals, and Co-C the subsequent formation of the Co(III) complex.

standard secondary KIE, and approaches or exceeds the theoretical maximum value of $\sim 1.4$ derived from changes in the out-of-plane $\mathrm{CH}_{2}$ bending vibration. ${ }^{34}$ This observation is in agreement with our proposed two-step mechanism, in which not only is the KIE of the first step resulting in a change in the rate constant, but additionally an equilibrium isotope effect (EIE) of the second step modifies the overall magnitude of the observed rate constant. ${ }^{35}$ The latter effect results from the preferential stabilization of deuterium in a bond with the greatest force constant. ${ }^{36}$

To identify the contributing factors of these two steps to the overall KIE, we analyzed and simulated the CVs upon sequentially adding more $7-\boldsymbol{d}_{2}$, in combination with cobalt ligated by $5 \mathrm{CF}_{3}$-pyrox 2 . The deuterated substrate displayed an activation energy barrier of $13.6 \mathrm{kcal} \mathrm{mol}^{-1}$ for the oxidative addition, a barrier of $9.9 \mathrm{kcal} \mathrm{mol}^{-1}$ for the addition of the benzylic radical to $\mathrm{Co}(\mathrm{II})$, with a $-5.5 \mathrm{kcal} \mathrm{mol}^{-1}$ exergonic reaction to form $\mathrm{Co}$ (III) (Figure $6 \mathrm{~b}$ ).

In comparison with the data for the protonated analogue (7), the deuterated substrate has a higher activation barrier for the formation of the radical and a lower activation barrier for the combination with $\mathrm{Co}$ (II). Consequently, there is a normal secondary KIE in the first step (Figure 6c), consistent with a change in hybridization from $\mathrm{sp}^{3}$ to $\mathrm{sp}^{2}$ in the formation of the radical. Contrastingly, an inverse $(<1.0)$ secondary KIE is observed in the second step, in which the $\mathrm{sp}^{2}$ hybridized benzylic radical undergoes a change to partial $\mathrm{sp}^{3}$ character in the transition state toward the $\mathrm{Co}$ (III) $-\mathrm{C}$ complex (Figure $6 \mathrm{~d})$. The EIE shows a small shift in the equilibrium position toward the starting benzylic radical for the deuterated substrate, consistent with favoring the $\mathrm{sp}^{2}$ hybridized carbon center in which the $\mathrm{C}-\mathrm{D}$ bond has more s-character, giving rise to a stronger bond.

Conducting CV simulations in this manner, thereby, allows the determination of the intricate factors affecting multiple kinetic steps, including changes in hybridization with KIE studies, which otherwise remain allusive with traditional techniques.

2.7. Analysis of Compounded Rate Constants with Hammett Parameters. With knowledge of the proposed mechanism involving halogen-atom abstraction and subsequent radical trapping by $\mathrm{Co}$ (II), we returned to the Hammett study to delineate the two effects. In the first step, abstraction of the bromine atom occurs with the buildup of both charge and radical character at the benzylic carbon. In comparable systems, it has been determined that for hydrogen-atom abstraction, correlations with $\sigma^{+}$are observed; electrondonating groups stabilize the buildup of positive charge at the benzylic carbon atom upon the abstraction of a hydrogen atom by an electrophilic radical, such as a bromine or $N$-oxyl radical. ${ }^{37}$ Conversely, correlations with $\sigma^{-}$are observed where the radical is nucleophilic, as seen with bromine-atom abstraction by tin- and silicon-centered radicals. ${ }^{38}$

Importantly, improved correlations are frequently observed when separating the atom abstraction processes into two components: a polar term for the development of partial charges in the transition state, and a distinct radical term for the delocalization of spin density. ${ }^{22 \mathrm{~d}}$ In this vein, Jiang et al. paired two terms to describe the effects of bromine-atom abstraction from benzyl bromides by silyl radicals. ${ }^{38 a, 39}$ The relative magnitudes of the $\rho$-value for each term then provide a reaction-specific comparison of polar to spin stabilization effects, a concept that has been used in a number of recent mechanistic investigations. ${ }^{40}$

When we applied this technique to our system, we observed an excellent correlation with the combination of $\sigma^{-}$and a conjugation parameter derived by Jackson, ${ }^{41}\left|\left(\sigma^{+}-\sigma\right) / n\right|$, where $n$ is a classification term used to determine the number of stabilizing electrons (Figure 7). The Jackson conjugation parameter was selected because the value of $\sigma^{\bullet}$ has not been tabulated for all of our substituents, so that we could identify a model with all of the available data. However, it should be noted that this term assumes that meta-substituents provide no (de)stabilization of spin density, an approximation that does not entirely account for meta-effects. ${ }^{42}$

The positive coefficient for $\sigma^{-}$in the correlation is in agreement with a halogen-atom abstraction in which the highspin (triplet-state) $)^{12} \mathrm{Co}(\mathrm{I})$ is reacting as a nucleophilic radical, as one would expect for an electron-rich metal center (Scheme 3). By comparing the relative magnitude of the coefficients for the two terms, we can observe that the stabilization of spin density is most significant. ${ }^{43}$ Additionally, the model has a higher weight for radical stability than one-step bromine-atom abstractions by either silicon ${ }^{38 a, b}$ or $\operatorname{tin}^{38 c}$ radicals, matching the two-step mechanism proposed herein.

2.8. Parameterization of Substrates and Modeling of Kinetic Data. As part of our program on utilizing multiple DFT-derived parameters to model complex chemical outcomes through multivariable linear-regression analysis, ${ }^{14}$ including within the setting of Hammett-type analysis, ${ }^{44}$ we next sought to determine whether we could model the kinetic outcome with only computationally derived parameters. ${ }^{45}$ The reasons 


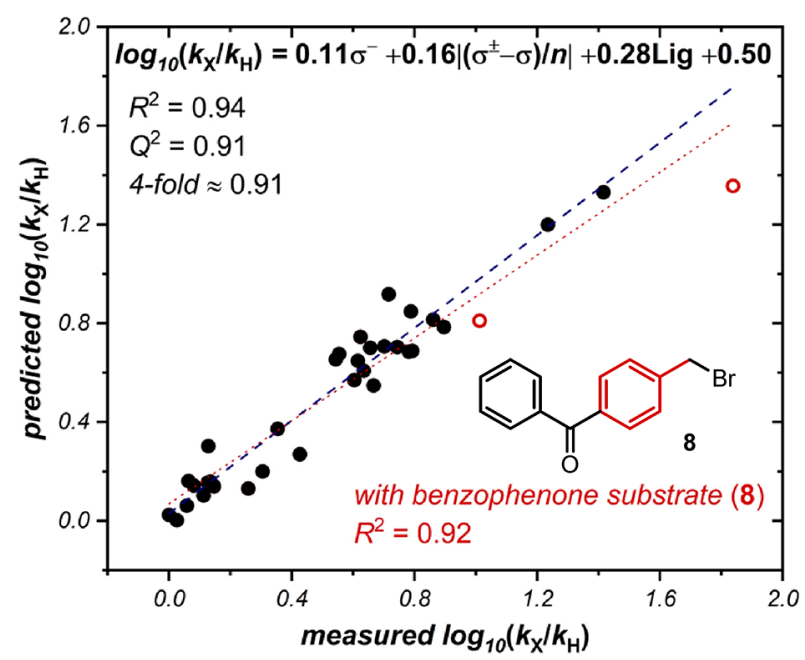

Figure 7. Unified Hammett model for the oxidative addition with both pyrox ligands, split into charge and radical stabilization terms. $n$ is a classification term for the number of stabilizing electrons, ${ }^{41}$ and Lig is a binary term included to account for the differential rate constants with the two pyrox ligands. Results of benzophenonederived substrate $\mathbf{8}$ with two different ligands depicted as red $\bigcirc$.

Scheme 3. Halogen-Atom Abstraction Favored by Stabilization of Both Negative Charge and Spin Density

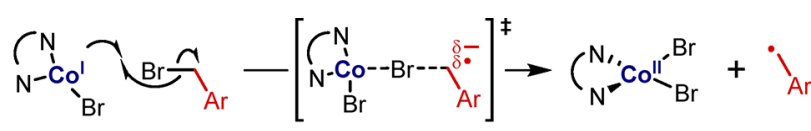

Co(I) behaves as a nucleophilic radical, creating both radical and carbanion character at the benzylic carbon in the bromine-atom abstraction transition state

for this were 3-fold: (a) first, we questioned whether parameters determined by DFT would allow delineation of the stabilization of charge and spin density; (b) $\sigma^{\bullet}$ values are not available for all of our substituents, and therefore we wanted a model that could better account for all of the possible groups, especially meta-substituents (which are not sufficiently modeled by Jackson's conjugation parameter ${ }^{41,42}$ ); and (c) to allow prediction of more complicated multisubstituted benzyl bromides. Specifically, we hoped our model could enable prediction of 3,4- and 3,5-disubstituted aromatic rings: while the additivity of Hammett $\sigma$-values is successful in some scenarios, ${ }^{46}$ it has several limitations. ${ }^{47}$

Considering the impact of the stabilization of both charge and radical character at the benzylic carbon in the transition state of the halogen-atom abstraction (cf., Scheme 3), we proposed that partial charge according to NBO and spin density at the benzylic carbon would appropriately describe both of these parameters, respectively. Upon computing a range of properties for the anion, cation, and radical, we determined a model incorporating the combination of the partial charge according to $\mathrm{NBO}$ of the radical at the benzylic carbon and the spin density according to NBO of the same carbon (Figure 8a). It is noteworthy that the $R^{2}=0.83$ and 0.86 for this combination of parameters with subsets of data corresponding to ligands $\mathbf{1}$ and 2, respectively.

The statistics of this model is substantially perturbed by the clustering of the data; two clusters are observed for the two ligands in the reaction with a range of largely electron-neutral substrates. To combat this, we added an additional ligand (5-
$\mathrm{CO}_{2} \mathrm{Me}$ substituted pyrox, 10) to provide a better spread of data by measuring the rate constants for the $\mathrm{Co}(\mathrm{I})$ oxidative addition with a smaller subset of benzyl bromides. A good model using the same substrate descriptors plus the Hammett $\sigma^{-}$value of the substituent on the pyridine was found (Figure $8 b)$. This $\sigma^{-}$parameter describes the electron-withdrawing nature of the ligand and is also correlated with the energy of the ligand's LUMO (see the Supporting Information), indicative of modulation of the nucleophilicity of the $\mathrm{Co}(\mathrm{I})$ complex. Interestingly, the $\mathrm{Co}(\mathrm{II}) / \mathrm{Co}(\mathrm{I})$ redox potential of the complex does not prove to be an appropriate parameter for modeling the rate constant, in contrast to previous reports of the $\mathrm{S}_{\mathrm{N}}$ 2-type oxidative addition of macrocyclic $\mathrm{Co}(\mathrm{I})^{8 \mathrm{~b}}$ and $\mathrm{Fe}(\mathrm{I})^{48}$ complexes to alkyl halides. Furthermore, substrate 8 is no longer a significant outlier in this model, a result that is discussed in detail in section 2.9.

In line with our goals for the parameterization study, we utilized a set of multisubstituted benzyl bromides to validate the statistics of the model. Sixteen validation points constructed from different combinations of substrates and ligands were tested (see the Supporting Information for details), resulting in a validation $R^{2}=0.73$, demonstrating the efficacy of the model to account for the effect of multiple electronic variations on reaction kinetics.

Moving aside from molecular descriptors that are directly analogous to Hammett parameters, we also identified a second model with similar statistics using the combination of the bond-dissociation energy (BDE) and the spin density (Figure $8 \mathrm{c}$ ). These two terms could describe the halogen-atom transfer and radical combination steps discretely, wherein the kinetics of the first step is modeled by the BDE, and the spin density is a correction factor for the combination of the kinetic and thermodynamic effects of the second step. Indeed, the simulated activation energy barriers for radical formation were found to be highly correlated $\left(R^{2}>0.99\right)$ with the bonddissociation energy, validating the results of the $\mathrm{CV}$ simulations (see the Supporting Information).

2.9. Solving Hammett Anomalies, Guided by Multivariable Linear-Regression Models. The models in Figure 8 demonstrate one major difference from those derived from the initial Hammett studies in Figures 2 and 7: the rate data for the benzophenone substrate $\mathbf{8}$ are no longer statistically anomalous, consistent with this substrate undergoing the same halogen-atom transfer mechanism as the other compounds. Indeed, it was an error in the effective $\sigma^{-}$Hammett value that results in a break in the linear free-energy relationship for this substrate.

To investigate the origin of this, we correlated DFTcomputed gas-phase acidities of various para-substituted phenols (from which $\sigma^{-}$values are derived), as well as parasubstituted toluene derivatives, against the $\sigma^{-}$values (see the Supporting Information). Consequently, we determined that the acidity of the para-COPh toluene is not appropriately predicted by the $\sigma^{-}$value. The reason for this was found to be a change in the conformation of both the anion and the conjugate acid depending on the nature of the atom $(\mathrm{O}$ in the case of phenols, or $\mathrm{C}$ in the case of toluenes). Conformational variations and their resultant perturbation in conjugation are a significant reason for the failings of Hammett correlations to account for ortho-substituents, ${ }^{44}$ but the effect of conjugation on distal groups is less common.

Benzophenone demonstrates a contorted conformation with changing dihedrals in the ground state, excited state, and 
a)
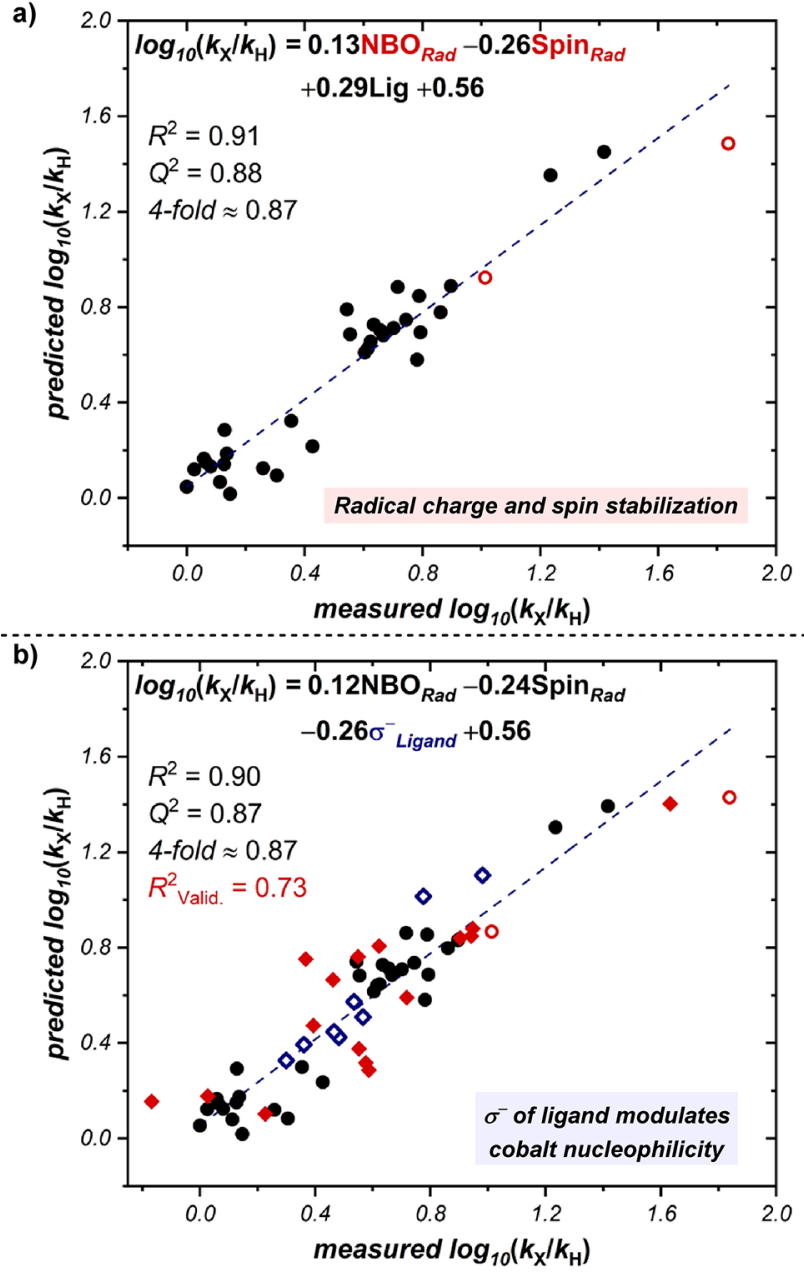

c)

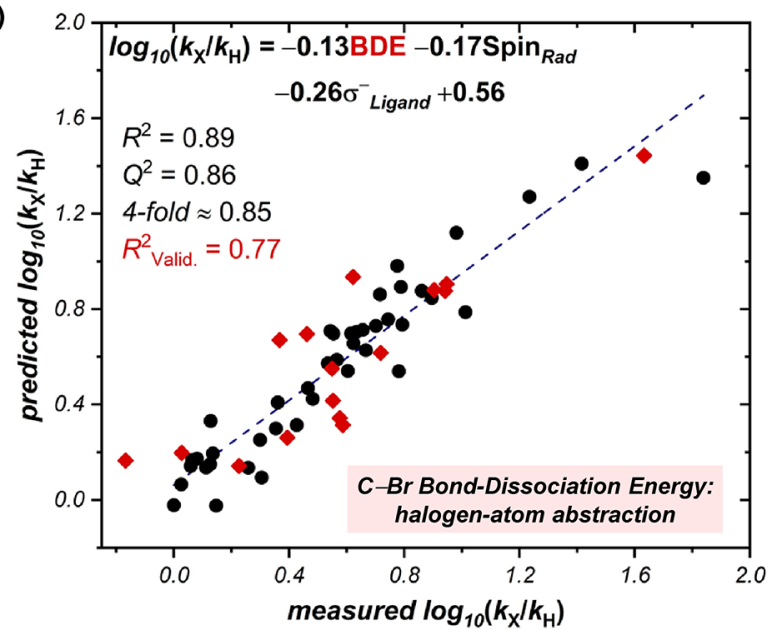

d)

Substrate Parameters: Charge, Spin and Bond Energy
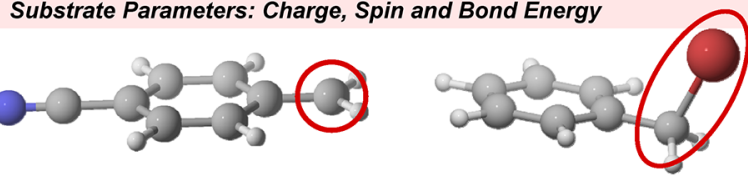

- $\mathrm{NBO}_{\text {Rad }}=$ Partial charge on benzylic carbon of radical

- $\operatorname{Spin}_{R a d}=$ Spin density on benzylic carbon of radical

- $\mathrm{BDE}=$ Bond-dissociation energy (bond strength)

Ligand Parameters: Nucleophilicity of Cobalt<smiles>COC(=O)c1ccc(C2=N[C@@H](Br)CO2)nc1</smiles>
$5 \mathrm{CO}_{2}$ Me-Pyrox

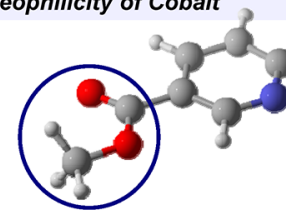

- Lig = Binary term to differentiate ligands 1 and 2

- $\sigma_{\text {Ligand }}^{-}=$Electron-withdrawal of substituent, correlates with LUMO

Figure 8. Multivariable linear-regression models for the Hammett series kinetic data. (a) Correlation with charge (NBO) and radical (spin) stabilization parameters in combination with a binary term $(\mathrm{Lig})$ to differentiate the two ligands. Results of benzophenone-derived substrate 8 with two different ligands depicted as red $\bigcirc$. (b) Addition of third ligand into the model (blue $\diamond$ ) and validation with multisubstituted benzyl bromides $($ red $\diamond)$. (c) Alternative model with bond-dissociation energy as a parameter, including validation (red $\diamond$ ). (d) Description of parameters and ligands utilized within this figure.

radical anion as a result of sterics between the two aromatic rings inhibiting planarity, which favors delocalization into the carbonyl (Figure 9). ${ }^{49}$ However, altering the substituents manipulates the competition between sterics and conjugation. For instance, we calculated that the carbonyl group lies $24^{\circ}$ out of the plane of a para-hydroxy-substituted ring, but a larger $27^{\circ}$ out of the plane for a para-methyl substituent. In this case, the delocalization of the oxygen lone pair favors conjugation and reduces the dihedral angle. Upon deprotonation, the dihedral

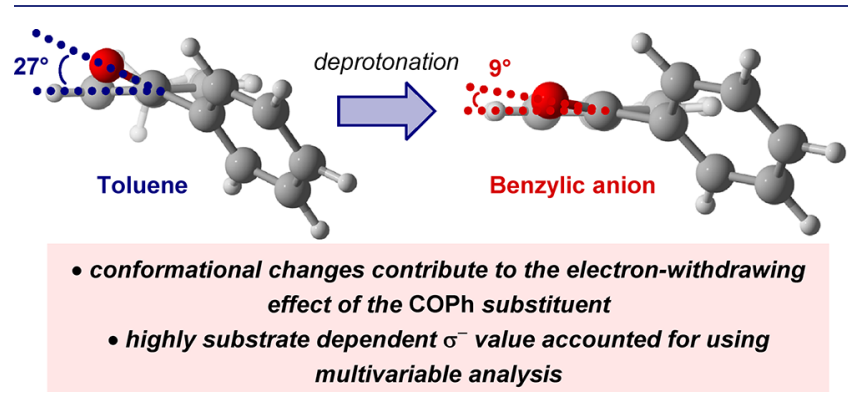

Figure 9. Conformation of para-COPh substituent (substrate 8) for toluene before and after deprotonation. angle is reduced in both cases to delocalize the charge onto the carbonyl oxygen. However, this effect is significantly greater for the benzylic anion $\left(9^{\circ}\right.$ dihedral) than for the phenoxide $\left(12^{\circ}\right.$ dihedral), as a consequence of the oxygen electronegativity changing the charge distribution.

Nominally, these differences in conformation appear modest, but for the toluene gas-phase acidity series we derive a $\sigma^{-}$value for substrate $\mathbf{8}$ of 0.99 (see the Supporting Information), significantly larger than the phenol value of 0.83 . This difference explains why substrate 8 appears as an anomaly in the Hammett relationship; $\sigma^{-}$is only an appropriate value for this substituent when considering reactivity of phenols. When corrected using the adjusted $\sigma^{-}$value, substrate 8 no longer appears as an anomaly in the Hammett plots of Figures 2 and 7 (see the Supporting Information). Through the parameterization program, we are able to observe the true result of this substrate, showing the power of this underlying technique. Additionally, we caution the future use of a COPh substituent as a point in a Hammett series without further analysis of conformational bias, as this may mislead the researcher to propose an alternative mechanistic rationale.

2.10. Beyond Hammett Relationships: Correlations Including Diverse Substrates. Given the parameters in the 
model in Figure 8c, we questioned whether this would allow extrapolation to alternative substrate classes. In the first instance, we were intrigued by modeling our data on the benzyl chloride (9) oxidative addition (see section 2.5). While Hammett models and other traditional linear free-energy relationships can only correlate the changes in aromatic substitution, and our first model in Figure 8a,b utilizes parameters from only the benzylic radical (thereby not encoding the nature of starting material halide), the bonddissociation energy term in Figure $8 \mathrm{c}$ was ideal to describe the nature of the halide leaving group in the halogen-atom abstraction.

Additionally, we were able to incorporate a range of secondary and tertiary substrates (studied in section 2.5), as well as benzhydryl bromide (13), into the model (Figure 10).

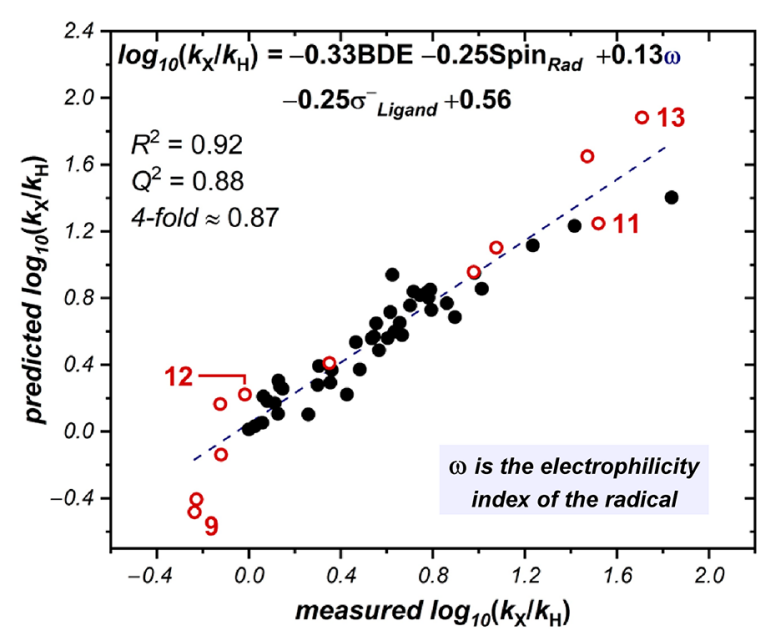

Extrapolation toward varied substrates, including benzyl chloride secondary/tertiary substrates and benzhydryl bromide:

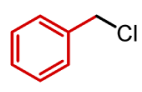

9 (with ligand 2)

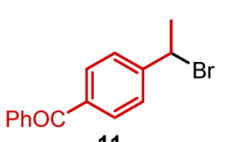

(with ligand 1)

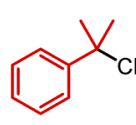

12

(with ligand 2)

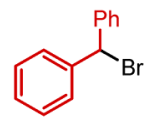

13 (with ligand 1)
Figure 10. Multivariable linear-regression model allows extrapolation to alternative substrate classes (depicted as red $\bigcirc$; see the Supporting Information for a full list of substrate/ligand combinations). $R_{\text {Valid }}^{2}=$ 0.77 ; validation points not shown for simplicity.

To add these substrates, we observed that the introduction of a new parameter, $\omega$, the electrophilicity index of the radical (a measurement of the energy stabilization upon acquiring additional electron density), ${ }^{50}$ was beneficial, presumably due to the large extrapolations in the parameters for bonddissociation energy and spin density when including the benzyl chlorides and benzhydryl bromide, respectively. This parameter has been reported to classify the nucleophilicity of a radical, ${ }^{51}$ which was also found to be integral to the exergonicity of the radical combination step in the $\mathrm{CV}$ simulations (section 2.4).

The new model allows comparisons between the kinetics of multiple substrate classes, beyond the correlations of a Hammett series with a single variable. Noticeably, some of these substrates represent significant extrapolations from other results with the same ligand; the combination of benzyl chloride (9) with ligand 2 has a rate constant 0.8 log units smaller than any benzyl bromides with the same ligand, while benzhydryl bromide (13) with ligand 1 has a rate constant 0.7 log units larger than any of the rate constants in Figure 2a.

Further applications toward expanding the scope of substrates studied in this manner could therefore theoretically allow the prediction of any oxidative addition kinetics that occur with pyrox-ligated $\mathrm{Co}(\mathrm{I})$ complexes through a halogenatom abstraction pathway.

\section{CONCLUSION}

We have investigated the mechanism of oxidative addition of $\mathrm{Co}(\mathrm{I})$ complexes into a variety of substituted benzyl bromides. The rate constants for the oxidative addition processes are readily determined by cyclic voltammetry at various scan rates, allowing rapid assessment of a Hammett relationship to evaluate electronic effects on the reaction. Further analysis of the cyclic voltammograms obtained with varying equivalents of substrate determined that the reaction is not a single transformation of $\mathrm{Co}(\mathrm{I})$ to $\mathrm{Co}(\mathrm{III})-\mathrm{C}$, but rather a two-step mechanism involving the initial formation of a benzylic radical, and the subsequent reversible formation of the $\mathrm{Co}$ (III)-C bond.

From these experiments, we propose that the mechanism proceeds through a halogen-atom abstraction process, a pathway found to be in agreement with kinetic isotope effects and the comparison between primary, secondary, and tertiary substrates. As a consequence, the complex, two-line Hammett plot can then be delineated as a combination of polar and radical stabilization effects according to the experimentally determined rate constant, a compounded value arising from the two-step mechanism. Finally, DFT-computed parameters can be utilized as diagnostic terms in place of Hammett parameters to successfully correlate calculated features of the benzyl halides to the observed rate constant. Furthermore, the multivariable statistical models allowed for rationalization of the anomalous points in the Hammett correlation, which arose from distal conformational differences between molecules.

The mechanistic knowledge gained in this study is integral to designing novel reaction methodologies with cobalt catalysts. Notably, although $\mathrm{Co}(\mathrm{III})-\mathrm{C}$ complexes can be afforded by oxidative addition and employed in further transformations, the existence of the equilibrium poses challenges for preventing catalytic turnover of benzyl bromides to their corresponding radicals. This challenge is a direct consequence of rapid reduction of any $\mathrm{Co}$ (II) within the electrode double layer under bulk electrolysis conditions. With an improved understanding of the principles behind these organometallic reaction steps, one can design new catalytic applications. Specifically, the multivariable correlation in Figure 10 facilitates the prediction of kinetic behavior for new substrate/ligand combinations outside the remit of the traditional Hammett series ubiquitous in physical organic chemistry.

Ultimately, we believe the techniques developed herein are of wide utility for the study of fundamental organometallic mechanisms. By simulating the cyclic voltammograms, we were able to obtain experimental values of multiple activation energies and equilibrium constants simultaneously, a significant challenge in complex, multistep processes such as those investigated. Therefore, these principles will be relevant in a range of applications for the purpose of disentangling complex reaction mechanisms. 


\section{ASSOCIATED CONTENT}

\section{S Supporting Information}

The Supporting Information is available free of charge on the ACS Publications website at DOI: 10.1021/jacs.9b10771.

Materials and methods, experimental and simulated cyclic voltammograms and kinetic data, parameters used in the modeling, additional models and correlations, discussion of gas-phase acidity computations, experimental procedures, characterization data and spectra for the synthesis of ligands and substrates, and coordinates of DFT-optimized structures (PDF)

\section{AUTHOR INFORMATION}

\section{Corresponding Authors}

*minteer@chem.utah.edu

*sigman@chem.utah.edu

\section{ORCID $\odot$}

Christopher Sandford: 0000-0002-4015-0674

Shelley D. Minteer: 0000-0002-5788-2249

Matthew S. Sigman: 0000-0002-5746-8830

\section{Notes}

The authors declare no competing financial interest.

\section{ACKNOWLEDGMENTS}

We would like to thank the National Science Foundation Center for Synthetic Organic Electrochemistry for funding (CHE-1740656). M.S.S. thanks the National Science Foundation (CHE-1763436) for support. C.S. thanks the EU for Horizon 2020 Marie Skłodowska-Curie Fellowship (grant no. 789399). The support and resources from the Center for High Performance Computing at the University of Utah, the Extreme Science and Engineering Discovery Environment (XSEDE, which is supported by the NSF (ACI-1548562) and provided through allocation TG-CHE190060), and the Metabolomics Core Facility at the University of Utah (mass spectrometers were purchased through NIH Office of the Director, grants 1S10OD016232-01, 1S10OD018210-01A1, and 1S10OD021505-01) are gratefully acknowledged.

\section{REFERENCES}

(1) (a) Labinger, J. A. Tutorial on Oxidative Addition. Organometallics 2015, 34, 4784-4795. (b) Halpern, J. Oxidative-addition reactions of transition metal complexes. Acc. Chem. Res. 1970, 3, 386392. (c) Hartwig, J. F. Oxidative Addition of Polar Reagents. Organotransition Metal Chemistry: From Bonding to Catalysis; University Science Books: Mill Valley, CA, 2010; pp 301-320.

(2) For reviews, see: (a) Tasker, S. Z.; Standley, E. A.; Jamison, T. F. Recent advances in homogeneous nickel catalysis. Nature 2014, 509, 299-309. (b) Diccianni, J. B.; Diao, T. Mechanisms of NickelCatalyzed Cross-Coupling Reactions. Trends Chem. 2019, DOI: 10.1016/j.trechm.2019.08.004. (c) For selected examples, see: Jones, G. D.; Martin, J. L.; McFarland, C.; Allen, O. R.; Hall, R. E.; Haley, A. D.; Brandon, R. J.; Konovalova, T.; Desrochers, P. J.; Pulay, P.; Vicic, D. A. Ligand Redox Effects in the Synthesis, Electronic Structure, and Reactivity of an Alkyl-Alkyl Cross-Coupling Catalyst. J. Am. Chem. Soc. 2006, 128, 13175-13183. (d) Zultanski, S. L.; Fu, G. C. Nickel-Catalyzed Carbon-Carbon Bond-Forming Reactions of Unactivated Tertiary Alkyl Halides: Suzuki Arylations. J. Am. Chem. Soc. 2013, 135, 624-627. (e) Biswas, S.; Weix, D. J. Mechanism and Selectivity in Nickel-Catalyzed Cross-Electrophile Coupling of Aryl Halides with Alkyl Halides. J. Am. Chem. Soc. 2013, 135, 16192-16197. (f) Zuo, Z.; Ahneman, D. T.; Chu, L.; Terrett, J. A.; Doyle, A. G.; MacMillan, D. W. C. Merging photoredox with nickel catalysis: Coupling of $\alpha$-carboxyl $\mathrm{sp}^{3}$-carbons with aryl halides. Science 2014, 345, 437-440. (g) Cornella, J.; Edwards, J. T.; Qin, T.; Kawamura, S.; Wang, J.; Pan, C.-M.; Gianatassio, R.; Schmidt, M.; Eastgate, M. D.; Baran, P. S. Practical Ni-Catalyzed Aryl-Alkyl CrossCoupling of Secondary Redox-Active Esters. J. Am. Chem. Soc. 2016, 138, 2174-2177. (h) Perkins, R. J.; Pedro, D. J.; Hansen, E. C. Electrochemical Nickel Catalysis for $\mathrm{Sp}^{2}-\mathrm{Sp}^{3}$ Cross-Electrophile Coupling Reactions of Unactivated Alkyl Halides. Org. Lett. 2017, $19,3755-3758$.

(3) For a review, see: Sperger, T.; Sanhueza, I. A.; Kalvet, I.; Schoenebeck, F. Computational Studies of Synthetically Relevant Homogeneous Organometallic Catalysis Involving $\mathrm{Ni}$, Pd, Ir, and Rh: An Overview of Commonly Employed DFT Methods and Mechanistic Insights. Chem. Rev. 2015, 115, 9532-9586.

(4) For selected DFT studies of one-electron oxidative addition of Ni into alkyl-heteroatom bonds, see: (a) Lin, X.; Phillips, D. L. Density Functional Theory Studies of Negishi Alkyl-Alkyl CrossCoupling Reactions Catalyzed by a Methylterpyridyl-Ni(I) Complex. J. Org. Chem. 2008, 73, 3680-3688. (b) Lin, X.; Sun, J.; Xi, Y.; Lin, D. How Racemic Secondary Alkyl Electrophiles Proceed to Enantioselective Products in Negishi Cross-Coupling Reactions. Organometallics 2011, 30, 3284-3292. (c) Li, Z.; Jiang, Y.-Y.; Fu, Y. Theoretical Study on the Mechanism of Ni-Catalyzed Alkyl-Alkyl Suzuki CrossCoupling. Chem. - Eur. J. 2012, 18, 4345-4357. (d) Wang, X.; Ma, G.; Peng, Y.; Pitsch, C. E.; Moll, B. J.; Ly, T. D.; Wang, X.; Gong, H. Ni-Catalyzed Reductive Coupling of Electron-Rich Aryl Iodides with Tertiary Alkyl Halides. J. Am. Chem. Soc. 2018, 140, 14490-14497. (e) Shu, W.; García-Domínguez, A.; Quirós, M. T.; Mondal, R.; Cárdenas, D. J.; Nevado, C. Ni-Catalyzed Reductive Dicarbofunctionalization of Nonactivated Alkenes: Scope and Mechanistic Insights. J. Am. Chem. Soc. 2019, 141, 13812-13821.

(5) For selected DFT studies of two-electron oxidative addition of $\mathrm{Ni}$ into alkyl-heteroatom bonds, see: (a) Zhang, S.-Q.; Taylor, B. L. H.; Ji, C.-L.; Gao, Y.; Harris, M. R.; Hanna, L. E.; Jarvo, E. R.; Houk, K. N.; Hong, X. Mechanism and Origins of Ligand-Controlled Stereoselectivity of Ni-Catalyzed Suzuki-Miyaura Coupling with Benzylic Esters: A Computational Study. J. Am. Chem. Soc. 2017, 139, 12994-13005. (b) Li, X.; Hong, X. Computational studies on Nicatalyzed $\mathrm{C}-\mathrm{O}$ bond activation of esters. J. Organomet. Chem. 2018, $864,68-80$.

(6) Diccianni, J. B.; Katigbak, J.; Hu, C.; Diao, T. Mechanistic Characterization of (Xantphos)Ni(I)-Mediated Alkyl Bromide Activation: Oxidative Addition, Electron Transfer, or Halogen-Atom Abstraction. J. Am. Chem. Soc. 2019, 141, 1788-1796.

(7) For a review, see: (a) Demarteau, J.; Debuigne, A.; Detrembleur, C. Organocobalt Complexes as Sources of Carbon-Centered Radicals for Organic and Polymer Chemistries. Chem. Rev. 2019, 119, 69066955. For selected examples, see: (b) Birke, R. L.; Huang, Q.; Spataru, T.; Gosser, D. K. Electroreduction of a Series of Alkylcobalamins: Mechanism of Stepwise Reductive Cleavage of the Co-C Bond. J. Am. Chem. Soc. 2006, 128, 1922-1936. (c) Weiss, M. E.; Kreis, L. M.; Lauber, A.; Carreira, E. M. Cobalt-Catalyzed Coupling of Alkyl Iodides with Alkenes: Deprotonation of Hydridocobalt Enables Turnover. Angew. Chem., Int. Ed. 2011, 50, 11125-11128. (d) Hossain, M. J.; Ono, T.; Yano, Y.; Hisaeda, Y. Learning From Vitamin $B_{12}$-Mediated Reactions: Cobalt(III)Carbon-Assisted Catalytic C-H Difluoroacylation of (Hetero)Arenes through Controlled-Potential Electrolysis. ChemElectroChem 2019, 6, 4199-4203.

(8) For selected mechanistic investigations of oxidative addition with polydentate ligated Co(I) complexes, see: (a) Zhou, D.-L.; Walder, P.; Scheffold, R; Walder, L. $\mathrm{S}_{\mathrm{N}} 2$ or Electron Transfer?? A new technique discriminates the mechanisms of oxidative addition of alkyl halides to corrinato- and porphyrinatocobalt(I). Helv. Chim. Acta 1992, 75, 995-1011. (b) Zhou, D.-1.; Gao, J.; Rusling, J. F. Kinetic Control of Reactions of Electrogenerated Co(I) Macrocycles with Alkyl Bromides in a Bicontinuous Microemulsion. J. Am. Chem. Soc. 1995, 117, 1127-1134. (c) Chen, D.; Fabre, P.-L.; Reynes, O. Electrocarboxylation of chloroacetonitrile by a Cobalt(I) complex of 
terpyridine. Electrochim. Acta 2011, 56, 8603-8610. (d) Costentin, C.; Passard, G.; Robert, M.; Savéant, J.-M. Concertedness in protoncoupled electron transfer cleavages of carbon-metal bonds illustrated by the reduction of an alkyl cobalt porphyrin. Chem. Sci. 2013, 4, 819-823.

(9) (a) Chung, W.-H.; Guo, P.; Wong, K.-Y.; Lau, C.-P. Electrocarboxylation of arylmethyl chlorides catalyzed by cobalt 6,6'-bis(2-hydroxyphenyl)-2,2'-bipyridine. J. Electroanal. Chem. 2000, 486, 32-39. (b) Fabre, P.-L.; Chen, D.; Reynes, O.; Chouini-Lalanne, N.; Sartor, V. Electrocatalytic carboxylation of chloroacetonitrile mediated by a $\mathrm{Co}(\mathrm{I})$ phenanthroline complex: Mechanistic and spectroscopic studies. J. Electroanal. Chem. 2013, 711, 25-31.

(10) For a review of DFT studies of oxidative addition of Pd into alkyl-heteroatom bonds, see: (a) Xue, L.; Lin, Z. Theoretical aspects of palladium-catalysed carbon-carbon cross-coupling reactions. Chem. Soc. Rev. 2010, 39, 1692-1705. For selected examples, see: (b) Ariafard, A.; Lin, Z. Understanding the Relative Easiness of Oxidative Addition of Aryl and Alkyl Halides to Palladium(0). Organometallics 2006, 25, 4030-4033. (c) Besora, M.; Gourlaouen, C.; Yates, B.; Maseras, F. Phosphine and solvent effects on oxidative addition of $\mathrm{CH}_{3} \mathrm{Br}$ to $\mathrm{Pd}\left(\mathrm{PR}_{3}\right)$ and $\mathrm{Pd}\left(\mathrm{PR}_{3}\right)_{2}$ complexes. Dalton Trans. 2011, 40, 11089-11094. (d) Pudasaini, B.; Janesko, B. G. Computational Mechanistic Study of Stereoselective Suzuki Coupling of an $\alpha$-Cyano-Activated Secondary Alkyl. Organometallics 2012, 31, 4610-4618. (e) Wolf, L. M.; Thiel, W. Origin of Inversion versus Retention in the Oxidative Addition of 3-Chloro-cyclopentene to Pd(0)Ln. J. Org. Chem. 2014, 79, 12136-12147.

(11) For selected DFT studies of oxidative addition of $\mathrm{Cu}$ into alkyl-heteroatom bonds, see: (a) Lin, C. Y.; Coote, M. L.; Gennaro, A.; Matyjaszewski, K. Ab Initio Evaluation of the Thermodynamic and Electrochemical Properties of Alkyl Halides and Radicals and Their Mechanistic Implications for Atom Transfer Radical Polymerization. J. Am. Chem. Soc. 2008, 130, 12762-12774. (b) Fang, C.; Fantin, M.; Pan, X.; de Fiebre, K.; Coote, M. L.; Matyjaszewski, K.; Liu, P. Mechanistically Guided Predictive Models for Ligand and Initiator Effects in Copper-Catalyzed Atom Transfer Radical Polymerization (Cu-ATRP). J. Am. Chem. Soc. 2019, 141, 7486-7497.

(12) Hickey, D. P.; Sandford, C.; Rhodes, Z.; Gensch, T.; Fries, L. R.; Sigman, M. S.; Minteer, S. D. Investigating the Role of Ligand Electronics on Stabilizing Electrocatalytically Relevant Low-Valent Co(I) Intermediates. J. Am. Chem. Soc. 2019, 141, 1382-1392.

(13) (a) Sandford, C.; Edwards, M. A.; Klunder, K. J.; Hickey, D. P.; Li, M.; Barman, K.; Sigman, M. S.; White, H. S.; Minteer, S. D. A synthetic chemist's guide to electroanalytical tools for studying reaction mechanisms. Chem. Sci. 2019, 10, 6404-6422. (b) Labbé, E.; Buriez, O. Fundamental Input of Analytical Electrochemistry in the Determination of Intermediates and Reaction Mechanisms in Electrosynthetic Processes. ChemElectroChem 2019, 6, 4118-4125.

(14) (a) Harper, K. C.; Sigman, M. S. Using Physical Organic Parameters To Correlate Asymmetric Catalyst Performance. J. Org. Chem. 2013, 78, 2813-2818. (b) Sigman, M. S.; Harper, K. C.; Bess, E. N.; Milo, A. The Development of Multidimensional Analysis Tools for Asymmetric Catalysis and Beyond. Acc. Chem. Res. 2016, 49, 1292-1301.

(15) Lips, S.; Waldvogel, S. R. Use of Boron-Doped Diamond Electrodes in Electro-Organic Synthesis. ChemElectroChem 2019, 6, $1649-1660$

(16) (a) Buriez, O.; Cannes, C.; Nédélec, J.-Y.; Périchon, J. Electrogeneration of cobalt(I) species stabilized by pyridine and its reaction with aryl halides. J. Electroanal. Chem. 2000, 495, 57-61. (b) Buriez, O.; Nédélec, J.-Y.; Périchon, J. Stability and reactivity of electrogenerated cobalt(I) towards aryl halides in the presence of additives such as vinyl acetate or methyl vinyl ketone: Application to the electrosynthesis of arylzinc compounds. J. Electroanal. Chem. 2001, 506, 162-169. (c) Polleux, L.; Labbé, E.; Buriez, O.; Périchon, J. Co $\mathrm{C}$ - and $\mathrm{Co}^{0}$-Bipyridine Complexes Obtained by Reduction of $\mathrm{CoBr}_{2}$ bpy: Electrochemical Behaviour and Investigation of Their Reactions with Aromatic Halides and Vinylic Acetates. Chem. - Eur. J. 2005, 11, 4678-4686.
(17) (a) Hansch, C.; Leo, A.; Taft, R. W. A survey of Hammett substituent constants and resonance and field parameters. Chem. Rev. 1991, 91, 165-195. For a discussion of "competing sets of standard $\sigma$ values" and their use in organometallic studies, see: (b) Puri, M.; Gatard, S.; Smith, D. A.; Ozerov, O. V. Competition Studies of Oxidative Addition of Aryl Halides to the (PNP)Rh Fragment. Organometallics 2011, 30, 2472-2482.

(18) Perrin, D. D.; Dempsey, B.; Serjeant, E. P. $p K a$ Prediction for Organic Acids and Bases; Chapman and Hall: London and New York, 1981.

(19) (a) Swain, C. G.; Langsdorf, W. P. Concerted Displacement Reactions. VI. m- and p-Substituent Effects as Evidence for a Unity of Mechanism in Organic Halide Reactions. J. Am. Chem. Soc. 1951, 73, 2813-2819. (b) Ballistreri, F. P.; Maccarone, E.; Mamo, A. Kinetics and mechanism of benzylation of anilines. J. Org. Chem. 1976, 41, 3364-3367. (c) Young, P. R.; Jencks, W. P. Separation of polar and resonance substituent effects in the reactions of acetophenones with bisulfite and of benzyl halides with nucleophiles. J. Am. Chem. Soc. 1979, 101, 3288-3294.

(20) (a) Brennan, M. R.; Kim, D.; Fout, A. R. A synthetic and mechanistic investigation into the cobalt(I) catalyzed amination of aryl halides. Chem. Sci. 2014, 5, 4831-4839. (b) Arrechea, P. L.; Buchwald, S. L. Biaryl Phosphine Based Pd(II) Amido Complexes: The Effect of Ligand Structure on Reductive Elimination. J. Am. Chem. Soc. 2016, 138, 12486-12493.

(21) For selected examples, see: (a) Michel, B. W.; Steffens, L. D.; Sigman, M. S. On the Mechanism of the Palladium-Catalyzed tertButylhydroperoxide-Mediated Wacker-Type Oxidation of Alkenes Using Quinoline-2-Oxazoline Ligands. J. Am. Chem. Soc. 2011, 133, 8317-8325. (b) Neel, A. J.; Milo, A.; Sigman, M. S.; Toste, F. D. Enantiodivergent Fluorination of Allylic Alcohols: Data Set Design Reveals Structural Interplay between Achiral Directing Group and Chiral Anion. J. Am. Chem. Soc. 2016, 138, 3863-3875. For an example of two separate correlations using $\sigma^{+}$for electron-rich substrates and $\left(\sigma+r^{-} \Delta \sigma^{-}\right)$, a Yukawa-Tsuno plot, for electrondeficient substrates, see: (c) D’Anna, F.; Frenna, V.; Macaluso, G.; Marullo, S.; Morganti, S.; Pace, V.; Spinelli, D.; Spisani, R.; Tavani, C. On the Rearrangement in Dioxane/Water of $(Z)$-Arylhydrazones of 5Amino-3-benzoyl-1,2,4-oxadiazole into (2-Aryl-5-phenyl-2H-1,2,3-triazol-4-yl)ureas: Substituent Effects on the Different Reaction Pathways. J. Org. Chem. 2006, 71, 5616-5624.

(22) (a) Fisher, T. H.; Meierhoefer, A. W. Substituent effects in freeradical reactions. A study of 4-substituted 3-cyanobenzyl free radicals. J. Org. Chem. 1978, 43, 224-228. (b) Dust, J. M.; Arnold, D. R. Substituent effects on benzyl radical ESR hyperfine coupling constants. The $\sigma_{\alpha}{ }^{*}$ scale based upon spin delocalization. J. Am. Chem. Soc. 1983, 105, 1221-1227. (c) Agirbas, H.; Jackson, R. A. Free radical reactions in solution. Part 9. Further $\sigma^{\bullet}$ values from decomposition of substituted dibenzylmercurials. J. Chem. Soc., Perkin Trans. 2 1983, 739-742. (d) Jiang, X.; Ji, G. A self-consistent and cross-checked scale of spin-delocalization substituent constants, the $\sigma^{\circ}$ JJ. J. Org. Chem. 1992, 57, 6051-6056. (e) Creary, X. Super Radical Stabilizers. Acc. Chem. Res. 2006, 39, 761-771.

(23) Amatore, C.; Pebay, C.; Scialdone, O.; Szunerits, S.; Thouin, L. Mapping Concentration Profiles within the Diffusion Layer of an Electrode: Application to Redox Catalysis. Chem. - Eur. J. 2001, 7, 2933-2939.

(24) Roth, H. G.; Romero, N. A.; Nicewicz, D. A. Experimental and Calculated Electrochemical Potentials of Common Organic Molecules for Applications to Single-Electron Redox Chemistry. Synlett 2016, 27, 714-723.

(25) Nocera, G.; Young, A.; Palumbo, F.; Emery, K. J.; Coulthard, G.; McGuire, T.; Tuttle, T.; Murphy, J. A. Electron Transfer Reactions: KOtBu (but not $\mathrm{NaOtBu}$ ) Photoreduces Benzophenone under Activation by Visible Light. J. Am. Chem. Soc. 2018, 140, 97519757.

(26) (a) Guttenplan, J. B.; Cohen, S. G. Quenching and reduction of photoexcited benzophenone by thioethers and mercaptans. J. Org. Chem. 1973, 38, 2001-2007. (b) Shen, Y.; Gu, Y.; Martin, R. sp $p^{3}$ C- 
$\mathrm{H}$ Arylation and Alkylation Enabled by the Synergy of Triplet Excited Ketones and Nickel Catalysts. J. Am. Chem. Soc. 2018, 140, 1220012209.

(27) (a) Rudolph, M.; Reddy, D. P.; Feldberg, S. W. A Simulator for Cyclic Voltammetric Responses. Anal. Chem. 1994, 66, 589A-600A. (b) Britz, D.; Strutwolf, J. Digital Simulations in Electrochemistry, 4th ed.; Springer International Publishing: Cham: Switzerland, 2016.

(28) (a) Bajo, S.; Laidlaw, G.; Kennedy, A. R.; Sproules, S.; Nelson, D. J. Oxidative Addition of Aryl Electrophiles to a Prototypical Nickel(0) Complex: Mechanism and Structure/Reactivity Relationships. Organometallics 2017, 36, 1662-1672. (b) Mohadjer Beromi, M.; Nova, A.; Balcells, D.; Brasacchio, A. M.; Brudvig, G. W.; Guard, L. M.; Hazari, N.; Vinyard, D. J. Mechanistic Study of an Improved Ni Precatalyst for Suzuki-Miyaura Reactions of Aryl Sulfamates: Understanding the Role of $\mathrm{Ni}(\mathrm{I})$ Species. J. Am. Chem. Soc. 2017, 139, 922-936. (c) Rummelt, S. M.; Zhong, H.; Léonard, N. G.; Semproni, S. P.; Chirik, P. J. Oxidative Addition of Dihydrogen, Boron Compounds, and Aryl Halides to a Cobalt(I) Cation Supported by a Strong-Field Pincer Ligand. Organometallics 2019, 38, 1081-1090. (d) Kawamata, Y.; Vantourout, J. C.; Hickey, D. P.; Bai, P.; Chen, L.; Hou, Q.; Qiao, W.; Barman, K.; Edwards, M. A.; Garrido-Castro, A. F.; deGruyter, J. N.; Nakamura, H.; Knouse, K.; Qin, C.; Clay, K. J.; Bao, D.; Li, C.; Starr, J. T.; Garcia-Irizarry, C.; Sach, N.; White, H. S.; Neurock, M.; Minteer, S. D.; Baran, P. S. Electrochemically Driven, Ni-Catalyzed Aryl Amination: Scope, Mechanism, and Applications. J. Am. Chem. Soc. 2019, 141, 63926402.

(29) The plausible dimerization of benzylic radicals was not included in these simulations. Adding this reaction into the CV kinetic model, we were able to ascertain that the rate constant for this step is less than $1.0 \times 10^{5} \mathrm{dm}^{3} \mathrm{~mol}^{-1} \mathrm{~s}^{-1}$. With a dimerization rate constant of this magnitude, we determined that the activation energy barriers for the radical formation and combination steps are unchanged. The exergonicity of the radical combination with $\mathrm{Co}(\mathrm{II})$ varies within a range of $\pm 0.2 \mathrm{kcal} \mathrm{mol}^{-1}$, which lies within the experimental error. For a discussion, see the Supporting Information.

(30) (a) Gutierrez, O.; Tellis, J. C.; Primer, D. N.; Molander, G. A.; Kozlowski, M. C. Nickel-Catalyzed Cross-Coupling of PhotoredoxGenerated Radicals: Uncovering a General Manifold for Stereoconvergence in Nickel-Catalyzed Cross-Couplings. J. Am. Chem. Soc. 2015, 137, 4896-4899. (b) Yin, H.; Fu, G. C. Mechanistic Investigation of Enantioconvergent Kumada Reactions of Raemic $\alpha$ Bromoketones Catalyzed by a Nickel/Bis(oxazoline) Complex. J. Am. Chem. Soc. 2019, 141, 15433-15440.

(31) Gómez-Gallego, M.; Sierra, M. A. Kinetic Isotope Effects in the Study of Organometallic Reaction Mechanisms. Chem. Rev. 2011, 111, 4857-4963.

(32) (a) Habibzadeh, S.; Rashidi, M.; Nabavizadeh, S. M.; Mahmoodi, L.; Hosseini, F. N.; Puddephatt, R. J. Steric and Solvent Effects on the Secondary Kinetic $\alpha$-Deuterium Isotope Effects in the Reaction of Methyl Iodide with Organoplatinum(II) Complexes: Application of a Second-Order Technique in Measuring the Rates of Rapid Processes. Organometallics 2010, 29, 82-88. (b) Aseman, M. D.; Rashidi, M.; Nabavizadeh, S. M.; Puddephatt, R. J. Secondary Kinetic Isotope Effects in Oxidative Addition of Benzyl Bromide to Dimethylplatinum(II) Complexes. Organometallics 2013, 32, 25932598.

(33) Holm, T. Kinetic Isotope Effects in the Reduction of Methyl Iodide. J. Am. Chem. Soc. 1999, 121, 515-518.

(34) Streitwieser, A.; Jagow, R. H.; Fahey, R. C.; Suzuki, S. Kinetic Isotope Effects in the Acetolyses of Deuterated Cyclopentyl Tosylates. J. Am. Chem. Soc. 1958, 80, 2326-2332.

(35) (a) Churchill, D. G.; Janak, K. E.; Wittenberg, J. S.; Parkin, G. Normal and Inverse Primary Kinetic Deuterium Isotope Effects for $\mathrm{C}-\mathrm{H}$ Bond Reductive Elimination and Oxidative Addition Reactions of Molybdenocene and Tungstenocene Complexes: Evidence for Benzene $\sigma$-Complex Intermediates. J. Am. Chem. Soc. 2003, 125, 1403-1420. (b) Kundu, S.; Choi, J.; Wang, D. Y.; Choliy, Y.; Emge, T. J.; Krogh-Jespersen, K.; Goldman, A. S. Cleavage of Ether, Ester, and Tosylate $\mathrm{C}\left(\mathrm{sp}^{3}\right)-\mathrm{O}$ Bonds by an Iridium Complex, Initiated by Oxidative Addition of $\mathrm{C}-\mathrm{H}$ Bonds. Experimental and Computational Studies. J. Am. Chem. Soc. 2013, 135, 5127-5143.

(36) (a) Bender, B. R. An Analysis of the Deuterium Equilibrium Isotope Effect for the Binding of Ethylene to a Transition-Metal Complex. J. Am. Chem. Soc. 1995, 117, 11239-11246. (b) Kennedy, C. R.; Guidera, J. A.; Jacobsen, E. N. Synergistic Ion-Binding Catalysis Demonstrated via an Enantioselective, Catalytic [2,3]-Wittig Rearrangement. ACS Cent. Sci. 2016, 2, 416-423.

(37) (a) Pearson, R. E.; Martin, J. C. The Mechanism of Benzylic Bromination with $\mathrm{N}$-Bromosuccinimide. J. Am. Chem. Soc. 1963, 85, 354-355. (b) DiLabio, G. A.; Franchi, P.; Lanzalunga, O.; Lapi, A.; Lucarini, F.; Lucarini, M.; Mazzonna, M.; Prasad, V. K.; Ticconi, B. Hydrogen Atom Transfer (HAT) Processes Promoted by the Quinolinimide- $N$-oxyl Radical. A Kinetic and Theoretical Study. J. Org. Chem. 2017, 82, 6133-6141.

(38) (a) Jiang, X.-K.; Ding, W. F.-X.; Zhang, Y.-H. The nucleophilic silyl radical: Dual-parameter correlation analysis of the relative rates of bromine-atom abstraction reactions as measured by a rigorous methodology. Tetrahedron 1997, 53, 8479-8490. (b) Kira, M.; Ishima, T.; Iwamoto, T.; Ichinohe, M. A Mechanistic Study of Reactions of Stable Disilenes with Haloalkanes. J. Am. Chem. Soc. 2001, 123, 1676-1682. (c) Menapace, L. W.; Loewenthal, M. B.; Koscielecki, J.; Tucker, L.; Passaro, L. C.; Montalbano, R.; Frank, A. J.; Marrantino, J.; Brunner, J. Organotin Hydride Reduction of Benzyl Bromides. Organometallics 2002, 21, 3066-3068.

(39) Jiang, X.-K. Establishment and Successful Application of the $\sigma_{\mathrm{JJ}}{ }^{\bullet}$ Scale of Spin-Delocalization Substituent Constants. Acc. Chem. Res. 1997, 30, 283-289.

(40) For selected examples, see: (a) Maestre, L.; Sameera, W. M. C.; Díaz-Requejo, M. M.; Maseras, F.; Pérez, P. J. A General Mechanism for the Copper- and Silver-Catalyzed Olefin Aziridination Reactions: Concomitant Involvement of the Singlet and Triplet Pathways. J. Am. Chem. Soc. 2013, 135, 1338-1348. (b) Bagchi, V.; Paraskevopoulou, P.; Das, P.; Chi, L.; Wang, Q.; Choudhury, A.; Mathieson, J. S.; Cronin, L.; Pardue, D. B.; Cundari, T. R.; Mitrikas, G.; Sanakis, Y.; Stavropoulos, P. A Versatile Tripodal Cu(I) Reagent for C-N Bond Construction via Nitrene-Transfer Chemistry: Catalytic Perspectives and Mechanistic Insights on $\mathrm{C}-\mathrm{H}$ Aminations/Amidinations and Olefin Aziridinations. J. Am. Chem. Soc. 2014, 136, 11362-11381. (c) Hedström, A.; Izakian, Z.; Vreto, I.; Wallentin, C.-J.; Norrby, P.O. On the Radical Nature of Iron-Catalyzed Cross-Coupling Reactions. Chem. - Eur. J. 2015, 21, 5946-5953. (d) Kong, C.; Jana, N.; Jones, C.; Driver, T. G. Control of the Chemoselectivity of Metal N-Aryl Nitrene Reactivity: $\mathrm{C}-\mathrm{H}$ Bond Amination versus Electrocyclization. J. Am. Chem. Soc. 2016, 138, 13271-13280.

(41) Dinçtürk, S.; Jackson, R. A. Free radical reactions in solution. Part 7. Substituent effects on free radical reactions: comparison of the $\sigma^{\bullet}$ scale with other measures of radical stabilization. J. Chem. Soc., Perkin Trans. 2 1981, 1127-1131.

(42) Fisher, T. H.; Dershem, S. M.; Prewitt, M. L. Meta-substituent effects on benzyl free-radical stability. J. Org. Chem. 1990, 55, 10401043.

(43) Kim, S. S.; Zhu, Y.; Lee, K. H. Thermal Isomerizations of Ketenimines to Nitriles: Evaluations of Sigma-Dot $\left(\sigma^{\bullet}\right)$ Constants for Spin-Delocalizations. J. Org. Chem. 2000, 65, 2919-2923.

(44) Santiago, C. B.; Milo, A.; Sigman, M. S. Developing a Modern Approach To Account for Steric Effects in Hammett-Type Correlations. J. Am. Chem. Soc. 2016, 138, 13424-13430.

(45) (a) Fernández, I.; Frenking, G. Correlation between Hammett Substituent Constants and Directly Calculated $\pi$-Conjugation Strength. J. Org. Chem. 2006, 71, 2251-2256. (b) Varaksin, K. S.; Szatylowicz, H.; Krygowski, T. M. Towards a physical interpretation of substituent effect: Quantum chemical interpretation of Hammett substituent constants. J. Mol. Struct. 2017, 1137, 581-588.

(46) Jaffé, H. H. A Reëxamination of the Hammett Equation. Chem. Rev. 1953, 53, 191-261.

(47) (a) Dippy, J. F. J.; Hughes, S. R. C. An examination of the principle of the additivity of substituent group influence in benzoic 
acids. Tetrahedron 1963, 19, 1527-1530. (b) Hęclik, K.; Dębska, B.; Dobrowolski, J. C. On the non-additivity of the substituent effect in ortho-, meta- and para-homo-disubstituted benzenes. RSC Adv. 2014, 4, 17337-17346.

(48) Lexa, D.; Mispelter, J.; Savéant, J. M. Electroreductive alkylation of iron in porphyrin complexes. Electrochemical and spectral characteristics of $\sigma$-alkylironporphyrins. J. Am. Chem. Soc. 1981, 103, 6806-6812.

(49) (a) Hoffmann, R.; Swenson, J. R. Ground- and excited-state geometries of benzophenone. J. Phys. Chem. 1970, 74, 415-420.

(b) Adam, F. C.; Aarons, L. J. Conformational Studies of the Benzophenone and Thiobenzophenone Radical Anions. Can. J. Chem. 1972, 50, 1427-1429. (c) Mantas, A.; Blanco, S. E.; Ferretti, F. H. The Effects of Substituents and Solvents on the Conformation of Benzophenones. Internet Electron. J. Mol. Des. 2004, 3, 387-399.

(50) (a) Parr, R. G.; Szentpály, L. v.; Liu, S. Electrophilicity Index. J. Am. Chem. Soc. 1999, 121, 1922-1924. (b) Domingo, L. R.; RíosGutiérrez, M.; Pérez, P. Applications of the Conceptual Density Functional Theory Indices to Organic Chemistry Reactivity. Molecules 2016, 6, 748.

(51) (a) De Vleeschouwer, F.; Van Speybroeck, V.; Waroquier, M.; Geerlings, P.; De Proft, F. Electrophilicity and Nucleophilicity Index for Radicals. Org. Lett. 2007, 9, 2721-2724. (b) Vleeschouwer, F. D.; Speybroeck, V. V.; Waroquier, M.; Geerlings, P.; Proft, F. D. An Intrinsic Radical Stability Scale from the Perspective of Bond Dissociation Enthalpies: A Companion to Radical Electrophilicities. J. Org. Chem. 2008, 73, 9109-9120. (c) Coote, M. L.; Lin, C. Y.; Beckwith, A. L. J.; Zavitsas, A. A. A comparison of methods for measuring relative radical stabilities of carbon-centred radicals. Phys. Chem. Chem. Phys. 2010, 12, 9597-9610. 